\title{
PERCEPTIONS OF EFFECTIVE IMPLEMENTATION OF APPLIED BEHAVIOUR ANALYSIS (ABA) IN SCHOOLS
}

by

\section{Heather Cowan}

Advanced Diploma, Behavioural Science Technology, George Brown College, Toronto, 2009 Bachelor of Arts, Psychology, Wilfrid Laurier University, Waterloo, 2008

A Major Research Paper

Presented to Ryerson University

in partial fulfillment of the requirements for the degree of

Master of Arts

in the Program of

Early Childhood Studies

Toronto, Ontario, Canada, 2013

(C) Heather Cowan 2013 


\section{Author's Declaration}

I hereby declare that I am the sole author of this MRP. This is a true copy of the MRP, including any required final revisions.

I authorize Ryerson University to lend this MRP to other institutions or individuals for the purpose of scholarly research.

I further authorize Ryerson University to reproduce this MRP by photocopying or by other means, in total or in part, at the request of other institutions or individuals for the purpose of scholarly research.

I understand that my MRP may be made electronically available to the public. 


\title{
PERCEPTIONS OF EFFECTIVE IMPLEMENTATION OF ABA IN SCHOOLS
}

(C) Heather Cowan 2013

Master of Arts

Early Childhood Studies

Ryerson University

\begin{abstract}
Policy/Program Memorandum Number 140 outlines the requirements for Ontario school boards to incorporate principles of Applied Behaviour Analysis (ABA) into school programs for students with Autism Spectrum Disorder (ASD). With increasing numbers of children being diagnosed with ASD, it is important to assess the facilitators and barriers in implementing this policy, and work towards effective academic and social inclusion. Through individual interviews and follow-up questionnaires, four behaviour therapists provided their perceptions and experiences of ABA in the classroom. A thematic analysis yielded five main themes: reinforcement in the classroom, consistency, $\mathrm{ABA}$ and behaviours in the classroom, collaboration, and attributions. These themes are interpreted using a social model of disability and a children's rights lens to answer the research question: what are the facilitators and barriers to the effective implementation of ABA in schools? Limitations, recommendations for future research, and practical recommendations are discussed.
\end{abstract}

Key words: Applied behaviour analysis, PPM 140, autism spectrum disorder, inclusion, social model of disability 


\section{Acknowledgements}

My family: Thank you for supporting me throughout my academic career, and in everything I do.

Dr. Kathryn Underwood: Thank you for your constant dedication and support throughout the ups and downs of this process. My learning and success would not have been possible without your guidance.

Dr. Kathleen Peets: Thank you for taking this project on with such short notice, and offering your perspective and support when I needed it the most.

Amanda Ajodhia-Andrews: Thank you for taking the role of second-reader, and being accessible, supportive, and flexible throughout the process.

Evelina Siwik and Lyndsay Macdonald: Thank you for keeping me sane during times of stress, excitement, and everything in between. This process would not have been the same without you.

Michael Kimel: Thank you for your support from the onset of this process, for taking the time to listen, and for providing me with encouragement along the way. 


\section{Dedication}

To every child with ASD I have worked with, and those I have not. You have taught me more than I could ever teach you. 


\section{Table of Contents}

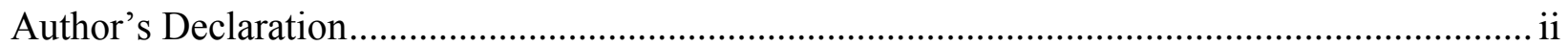

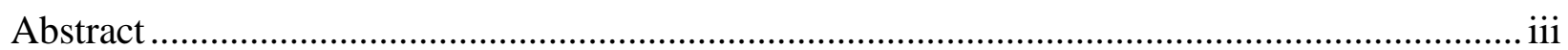

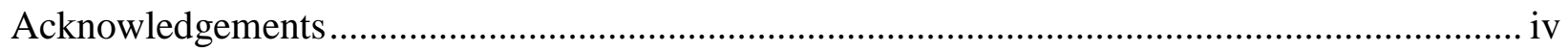

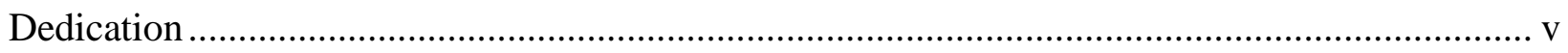

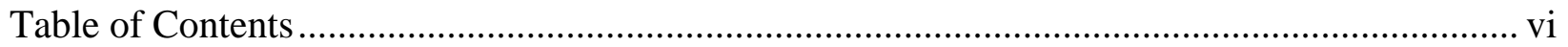

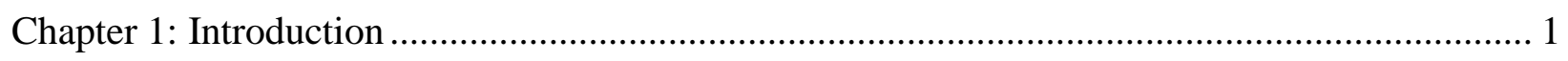

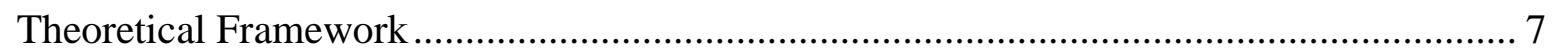

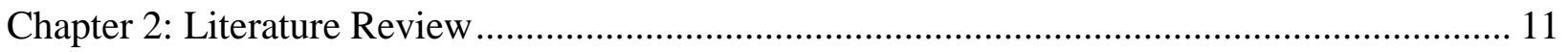

ASD

ABA …………… 12

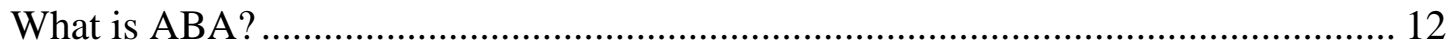

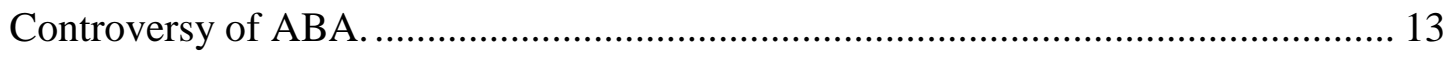

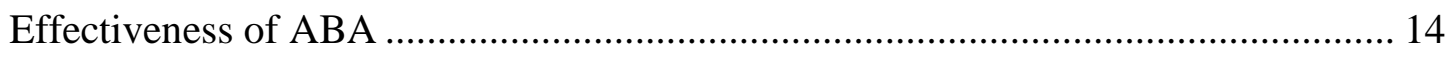

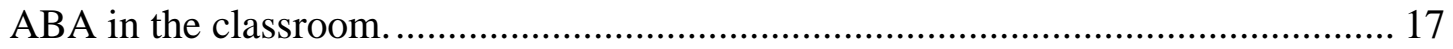

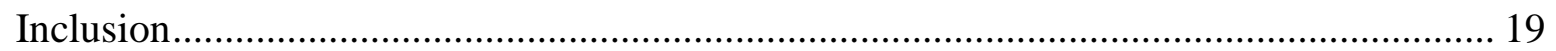

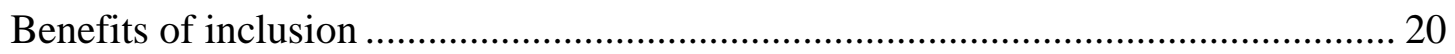

Factors affecting inclusion ............................................................................... 21

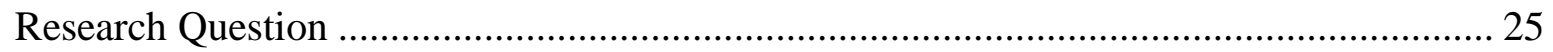

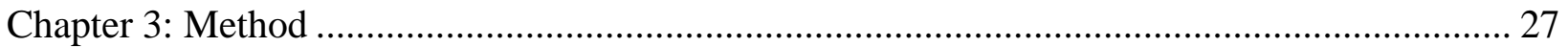


Participants...

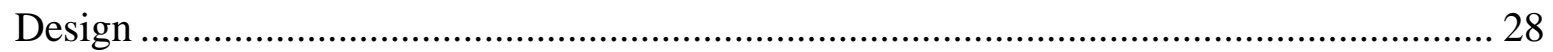

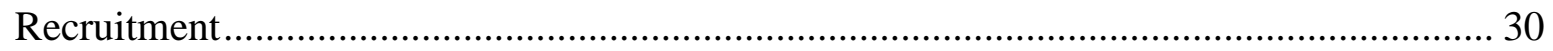

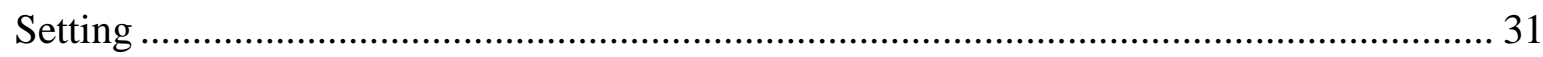

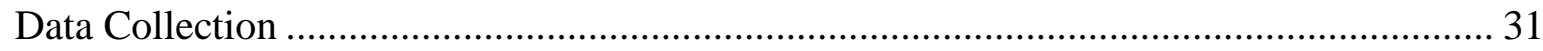

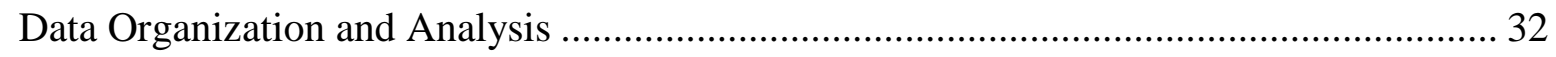

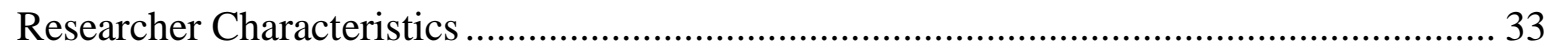

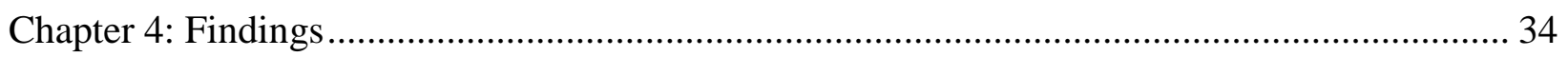

Participant Characteristics .............................................................................. 34

Thematic Analysis of Interview Data ...................................................................... 35

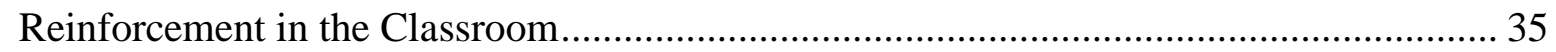

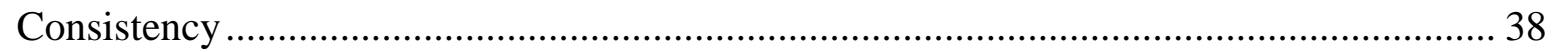

ABA and Behaviours in the Classroom ................................................................ 40

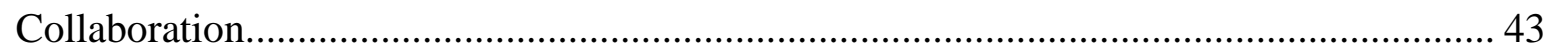

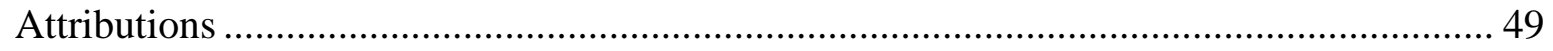

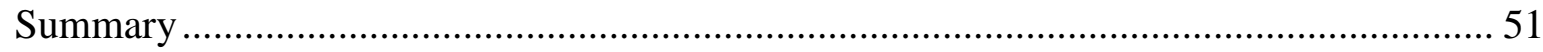

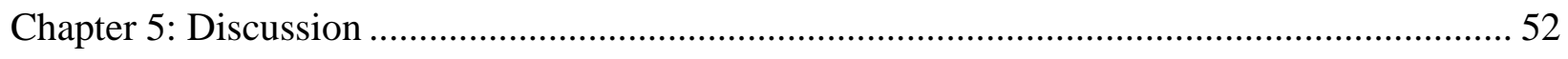

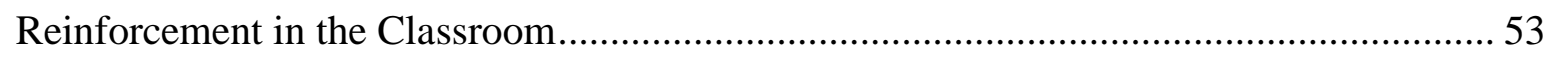

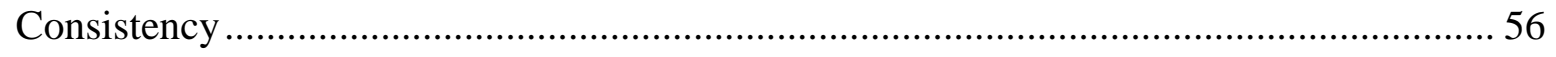

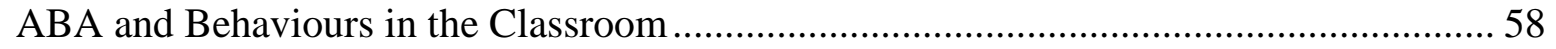


Collaboration.

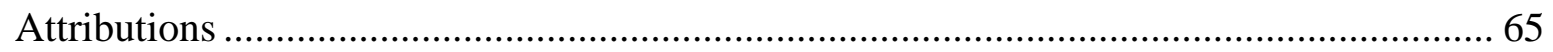

What Would an Inclusive Classroom With ABA Include? ............................................ 66

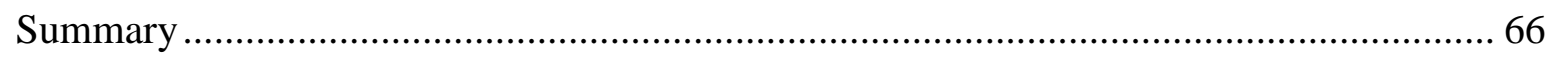

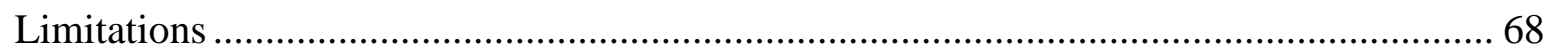

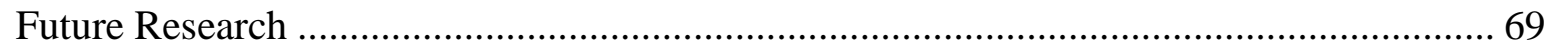

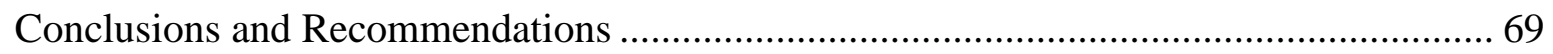

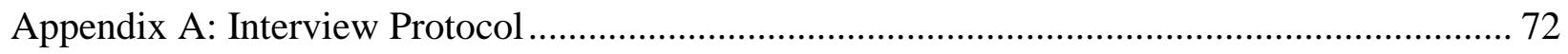

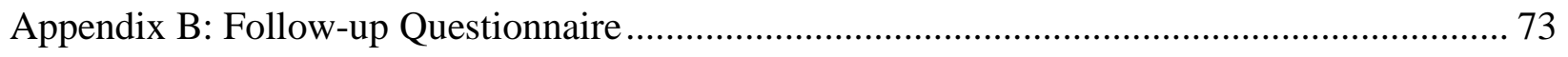

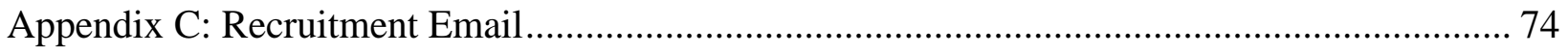

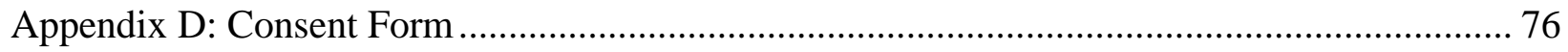

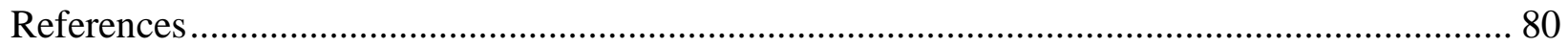




\section{Chapter 1: Introduction}

Autism Spectrum Disorder (ASD) is a developmental disability which affects communication, social interactions, behaviours, and at times language and cognitive ability (Geneva Centre for Autism, 2007). Some children with ASD use a treatment process known as Applied Behaviour Analysis (ABA) (Dillenburger \& Keenan, 2009); however, due to high costs and long wait lists, many children with ASD do not receive such therapy (Gordon, 2012a). With more than 10,000 children with ASD receiving special education services in Ontario (Ontario Ministry of Education, 2011), the Ministry of Education established Policy/Program Memorandum Number 140 (PPM 140). The policy outlines the use of ABA in schools to increase the education and inclusion of children with ASD (Ontario Ministry of Education, 2007). Although previous research investigates facilitators and barriers to inclusion, little is currently known about the factors that impact the implementation of PPM 140. The current study aims to investigate the facilitators and barriers that impact the application of ABA in schools from the perceptions and experiences of behaviour therapists.

Although Ontario school boards aim to support an inclusive educational system (Ontario Ministry of Education, 2009), children with disabilities are placed in segregated special education classes when it is believed that the general education class cannot meet their needs (Ontario Government, 2005). This type of segregation is evidence that although the educational system may strive to be inclusive, Ontario's classrooms are not all fully inclusive. PPM 140 was established in 2007, and is possible evidence of Ontario schools striving to be more inclusive of children with ASD.

ASD is a neurological developmental disorder that affects verbal and non-verbal communication and social interactions, and is accompanied by repetitive behaviours and/or 
restricted interests (American Psychological Association, 2013). Difficulty with communication (as defined by societal norms) and understanding other people's thoughts and needs, and in turn their own thinking process and emotional responses are often not understood by others. The result can be that people, particularly children with ASD, may exhibit externalizing behaviours such as aggression, tantrums, non-compliance, or self-injury, or internalized behaviours such as being very quiet, withdrawn or disinterested in other people (Schneiter \& Devine, 2001). Because classrooms are often governed by a set of behavioural norms, children with ASD can have difficulty complying with expectations in a school classroom. As ASD lies on a spectrum, and other individual characteristics are part of the learning and temperament of children, the individuals with this diagnosis are very heterogeneous. The severity of symptoms and the level of functioning in society vary across environments (Autism Society of Canada, 2013). In addition, the domains in which ASD manifests, varies amongst individuals. For example, some people with ASD have delays in language and cognitive development, while others have average or above average intelligence and no language delays (Autism Society of Canada, 2013). Some also appear very socially withdrawn while others are perceived as overly social. These variances are used to characterize people with ASD as high or low functioning. Although many people with ASD develop skills such as language and communication, they do so in different ways than people who do not have ASD (Geneva Centre for Autism, 2007). Just as every child has individual characteristics and needs, children with ASD have a unique set of abilities to bring to the classroom environment.

The basic principles of behaviourism are often used to teach children with ASD (Dillenburger \& Keenan, 2009). ABA is a set of techniques systematically used to modify behaviour and teach new skills (Baer, Wolf, \& Risley, 1968) by applying the principles of 
behaviourism. The theory of behaviourism is based on the premise that behaviour is observable and controlled by its consequences (Skinner, 1938). When a reinforcing stimulus follows a behaviour it is more likely to occur in the future. When a punishing stimulus follows a behaviour it is less likely to occur in the future (Lovaas, 1987). Principles of behaviourism guide human learning and are seen everywhere in society. For example, a child will finish their vegetables to be reinforced with dessert, a student is motivated to write a good essay to be reinforced by a good mark, an adult goes to work to get a paycheck, or a person tells a joke to encourage other people to laugh. Research on reinforcement also includes schedules of reinforcement in regard to the frequency, duration, immediacy, intensity, saturation, consistency, and type of reinforcement (Skinner, 1989). People with ASD are often very discrete learners and have difficulty learning naturally from their environment. ABA manipulates the environment as skills or behaviours are clearly defined and measured, broken down into small, basic steps and explicitly and systematically taught using reinforcement (Baer, Wolf, \& Risley, 1968).

At one time, children with ASD were largely educated in segregated classrooms (Bennett, Dworet, \& Weber, 2008). Currently, special education services are being provided to more than 10,000 children with ASD in Ontario (Ontario Ministry of Education, 2011), and an increasing number of children are getting these services in regular classrooms with varying degrees of support (Ontario Ministry of Education, 2009). The presence of a child with ASD in a classroom does not necessarily indicate an environment of inclusion. In these cases, the classrooms are more physically inclusive as opposed to educationally and socially inclusive (Buysse, Skinner, \& Grant, 2001). For the purpose of this paper, the United Nations Educational, Scientific and Cultural Organization (UNESCO) (2005) definition of inclusion will be used to define inclusive education: 
Inclusion is seen as a process of addressing and responding to the diversity of needs of all learners through increasing participation in learning, cultures and communities, and reducing exclusion within and from education. It involves changes and modifications in content, approaches, structures and strategies, with a common vision which covers all children of the appropriate age range and a conviction that it is the responsibility of the regular system to educate all children. (p. 13).

The Ontario government has acknowledged ABA as a "highly effective method" (Ontario Ministry of Education, 2007) and children diagnosed with ASD may be funded by the province to receive $\mathrm{ABA}$ therapy, depending on the severity of their diagnosis (Ontario Ministry of Children and Youth Services, 2011). There is little information, however, available to the public about the exact number of children with ASD receiving funding from the province. According to a survey of regional ABA service providers by the Toronto Star, approximately 1,400 children with ASD are enrolled in Ontario funded ABA programs (Gordon, 2012b). This number does not include children who have not been diagnosed, or are not enrolled in a provincial program and may be receiving private $\mathrm{ABA}$ services, other forms of therapy, or no services at all. There are approximately 1,700 children with ASD waiting for funding (Gordon, 2012b). Unfortunately, this therapy is very expensive, costing between $\$ 40,000$ and $\$ 75,000$ per year (Ontario Ministry of Children's Services and Ontario Ministry of Community and Social Services, 2003), the average wait time is one to four years (Gordon, 2012a). Intervention at an early age has been proven to be an extremely important factor in the success of ABA (Lovaas, 1987), children are typically funded for a limited number of years, and are often fully transitioned into the school system within their elementary years (Gordon, 2012a). PPM 140 is in place to extend the use of 
ABA beyond a therapy setting into the classroom, providing an inclusive educational environment for children with ASD.

The UNESCO definition of inclusion highlights both the placement and supports that are needed to ensure an inclusive environment. Incorporating ABA into schools reflects the appropriate changes in teaching approaches and strategies. The school takes the responsibility of educating all children, including those with ASD. PPM 140 outlines basic principles, rationale, and requirements of incorporating ABA into school programs for students with ASD in the province of Ontario (Ontario Ministry of Education, 2007). One requirement stated by the policy is "school boards must offer students with ASD special education program and services, including, where appropriate, special education programs using ABA methods" (p. 3). Students' programming must incorporate significant ABA methods where appropriate, for example, the use of functional behavioural assessments for behavioural issues. The main principles of ABA programming for students with ASD, as outlined by PPM 140, are an individualized program, the use of positive reinforcement, data collection and analysis, and a focus on the generalization of skills.

The second requirement described in PPM 140 states "school board staff must plan for the transition between various activities and settings involving students with ASD” (p. 5). There are many types of transitions that students with ASD face. These include the transition into school, between grades, between activities and settings, between schools, and exiting school. According to PPM 140, methods of ABA should be incorporated to support children in these transitions, and planning should include consultation with parents and community professionals (such as behaviour therapists) when applicable. PPM 140 also recommends other Ministry of Education documents consistent with the policy: Special Education Transformation: The Report 
of the Co-Chairs With the Recommendations of the Working Table on Special Education (Ontario Ministry of Education, 2006), Education for All: The Report of the Expert Panel on Literacy and Numeracy Instruction for Students With Special Education Needs, Kindergarten to Grade 6 (Ontario Ministry of Education, 2005a), Planning Entry to School: A Resource Guide (Ontario Ministry of Education, 2005b), The Individual Education Plan (IEP): A Resource Guide (2004), and Transition Planning: A Resource Guide (Ontario Ministry of Education, 2002). To assist with the implementation of PPM 140, ASD consultants are hired by the school board through a regional ABA service provider experienced in supporting people with intellectual disabilities. ASD consultants train and consult with teachers in regard to general implementation of ABA in order to improve supports for children with ASD in the public school system. These training and consultation services are provided at the request of the school, and often take place in the form of professional development workshops and short-term consultation (Surrey Place Centre, n.d.).

PPM 140 (Ontario Ministry of Education, 2007) outlines the requirements for Ontario school boards to incorporate principles of ABA into school programs for students with ASD, to work towards the inclusion of these children in schools and society as a whole. With an increasing number of children being diagnosed with ASD (National Epidemiologic Database for the Study of Autism in Canada, 2012), it is important to investigate the barriers and facilitators that impact the academic and social inclusion of these children. Factors in physical and social environments can act as either facilitators or as barriers to the functioning of a person with a disability (World Health Organization, 2002). Facilitators are factors that assist in the functioning and participation of a person within a society. On the contrary, barriers hinder functioning, resulting in disability. Therefore, it is important to investigate both the facilitators 
and barriers to successful implementation of ABA in schools and work towards effective academic and social inclusion.

In the present study, behaviour therapists discuss their perceptions of facilitators and barriers to ABA in schools. Since they likely face these issues while working in schools, they will report their attributions of the cause of these factors. Attribution theory explains the way in which people explain the reasons for behaviours and events in order to make sense of their world. According to attribution theory, people often make causal explanations about other's behaviours (Kelley, 1973) and this affects the way they understand and react to such behaviour (Kelley \& Michela, 1980). People attribute behaviour to internal or external causes. Internal causes are personality factors such as a person's motivation or ability. External causes are situational, such as social or physical circumstances. People tend to attribute other's actions as internal, whereas they attribute their own actions as external, known as attribution error (Pettigrew, 1979). Attribution theory is important to consider in the present study, as behaviour therapists are the only professional group being asked to discuss their perceptions of a social phenomenon that includes a variety of groups and individuals, and their attributions should therefore be considered as a limitation in interpretation.

\section{Theoretical Framework}

The present study uses both the social model of disability and a children's rights perspective as a lens to view the implementation of ABA in schools. These two frameworks have informed the researcher and impacted the way literature was reviewed as well as the choice of methodology. The social model of disability is used to view ABA as a teaching method for children with ASD. Then a children's rights perspective is used to discuss the rights of the child in regard to the application of ABA in the school system. 
Principles of ABA can be applied to modify behaviour and teach new skills, and are often used to teach people with ASD (Dillenburger \& Keenan, 2009). When the goals are focused on normalization, such as reducing socially unacceptable behaviours (Stahmer, Schreibman, \& Cunningham, 2011), the use of ABA is in line with the medical model of disability. The medical model of disability views disability as a result of a problem within the individual. There is a focus on rehabilitation in order to cure the disability and normalize the individual (Barnes, Mercer, \& Shakespeare, 1999). ABA has been critiqued since the goals of ABA programming are often aligned with the medical model of disability (Ortega, 2009). For example, selfstimulatory or "stimming" behaviours are often targeted for therapy since they are seen as socially unacceptable, although these behaviours serve a sensory function to the individual, often as a coping mechanism (Nolan \& McBride, 2013). As ABA can be implemented to normalize a person's behaviours, tension exists between ABA and the social model of disability. However, the way in which ABA aligns with a model of disability is dependent on the goals of the programming, not on the principles of $\mathrm{ABA}$. When $\mathrm{ABA}$ is used as a teaching method, not as an intervention, $\mathrm{ABA}$ is in line with the social model of disability. The social model of disability views disability as a result of barriers within society. The focus is on removing these barriers to support full participation (Barnes et al., 1999).

A main goal of education for all children is to learn to communicate their needs and thoughts, which can be a challenge for children with ASD. Children learn how to communicate in school, use language skills to acquire more knowledge, understand information, and increase concept development. A central goal in teaching children with ASD is to explicitly teach communication. This starts with basic requests for desired items or activities, and progresses to more complex communication and language use (Sundberg \& Partington, 1998). Although 
communication is a common goal of both ABA programs and the general education system, there is a difference in how this communication is taught. Principles of ABA are often used in teaching communication skills to children with ASD (Makrygianni \& Reed, 2010). Teaching a child to communicate, for example, to ask for a glass of water, is not about changing the child or curing their disability. It is about teaching them to meet their needs and learning to express themselves. Research has shown an increase in communication is also found to decrease selfinjurious behaviours (Schneiter \& Devine, 2001). Therefore, using principles of ABA to teach a child with ASD to communicate does not need to be aligned with the medical model of disability, as the goal does not need to be rehabilitation or normalization. ABA can be in line with the social model of disability when the focus is on learning and participation, and removing environmental barriers that result in disability. However, when ABA focuses on what are deemed to be undesirable behaviours and attempts to change behaviours that may serve an important function for a child with ASD, then it is not aligned with a social model of disability.

All children, including those with ASD, have the right to an education, and ABA has been associated with quantifiable increases in children's intellectual, language, academic, skill, or behavioural domains (Makrygianni \& Reed, 2010). Using a children's rights perspective, children with disabilities have the right to full inclusion within society. The Committee on the Rights of the Child (2006) outlines that education should be accessible; appropriate modifications should be made for children with disabilities; and programming should be individualized since each child has individual needs. Children should have access to free education. If children with $\mathrm{ASD}$ can only receive $\mathrm{ABA}$ at a cost, this violates their rights. Including ABA in the school system is a free opportunity to receive such teaching. Teachers need to be trained in different teaching methods and techniques, to provide an effective 
education and curriculum, and to meet the individual needs of children (Committee on the Rights of the Child, 2006).

The gains associated with ABA (Makrygianni \& Reed, 2010) should be an accessible option to all children with ASD, and children who need support in education have the right to access this support in the general education system. If ABA is a method that works, it is a child's right to receive this method of teaching. This is especially true in school, an environment where a majority of a child's learning takes place. Implementing a teaching method that is not effective results in a barrier to education; it is disabling. Using an effective teaching method for each child is removing the barrier to learning; it is the child's right. 


\section{Chapter 2: Literature Review}

A review of the literature discusses ASD, ABA, and inclusion. Characteristics of ASD are outlined to provide an understanding of disability. The theory of behaviourism behind ABA is explained along with the fundamental principles, as ABA is a broad term that can be applied in different ways, and is surrounded by debate. This controversy is discussed and followed by an explanation of how ABA can be effective and applied using a social model of disability lens. Consistent with this theoretical framework, the academic, social, language, and cognitive benefits of inclusion are presented, along with research discussing how organizational, attitudinal, knowledge, and collaboration factors affect inclusion. A summary of the literature leads to the current study's research question about the factors affecting ABA in the classroom. ASD

ASD is the most common neurological disorder among children (Geneva Centre for Autism, 2007). Approximately 1 in 88 children in Canada are diagnosed with ASD (1 in 54 boys) which is an increase of $78 \%$ over the past 6 years (Autism Speaks, 2013). According to the Fifth Edition of the Diagnostic and Statistical Manual of Mental Disorders (DSM-V), a diagnosis of ASD includes the following criteria which must begin in early childhood: significant social and communication deficits, along with repetitive and restricted behaviours, interests, and activities (American Psychological Association, 2013). The majority of children with ASD have a deficit in language, communication and/or social interactions (as defined by societal norms), as well as difficulty attending (often due to sensitivity to sensory stimuli in the environment) which can interfere with learning in a typical classroom (Fernell et al., 2011). Although there are commonalities between individuals, the diagnosis is on a spectrum because every child with ASD is different, and the severity of symptoms varies across domains (Autism Society of 
Canada, 2013). For example, some people with ASD are very withdrawn and show little interest in others, acquire little or no language or other means of communication, engage in self-injurious behaviours, have great difficulty caring for themselves, or otherwise face many challenges functioning in society (Geneva Centre for Autism, n.d.). On the other end of the spectrum, people with ASD may have difficulty in social situations but otherwise function independently in society (Geneva Centre for Autism, n.d.).

\section{ABA}

What is ABA? Principles of ABA are used to teach children with ASD (Dillenburger \& Keenan, 2009). The main principles of ABA include reinforcement, stimulus control, motivation, and generalization (Hayward, Gale, \& Eikeseth, 2009). Reinforcement is a consequence which increases the chances of a behaviour occurring again in the future. Reinforcement can be through attention, access to tangibles, escape, or sensory stimulation. What is reinforcing to one child may not be reinforcing to another. Stimulus control is a stimulus in the environment which signals that reinforcement will occur given a certain behaviour, such as responding to a question. Motivation is focused on providing child-specific reinforcement, for example, when teaching a child to read, using reinforcing materials such as a book of interest to the child. Generalization is learning to apply skills across multiple people, places, and stimuli, with a goal of reinforcement occurring naturally in the environment (Hayward et al., 2009). These principles of ABA can be used to teach skills and behaviours such as communication, academics, social skills, life skills, and play skills (Hayward et al., 2009).

$\mathrm{ABA}$ is often believed by educators, and even by some behaviour therapists, to be fully or mainly comprised of discrete trial training (DTT) (Steege, Mace, Perry, \& Longenecker, 2007). DTT is a one-to-one teaching procedure that breaks skills into small steps. It is composed 
of an instruction given by the teacher, a prompt if necessary, a response from the child, a consequence provided by the teacher (reinforcement or error-correction), and an inter-trial interval (Smith, 2001). This process is repeated multiple times and prompts and reinforcers are faded as learning takes place. As simple behaviours are learned, they are systematically shaped into combinations of behaviours. Each response or behaviour is recorded and evaluated. The process can be adjusted when the desired skill or behaviour is not achieved. Although DTT is an effective component of $\mathrm{ABA}$, it is only one component of a comprehensive approach to working with children with ASD.

Steege et al. (2007) stress the importance of implementing many components of ABA in addition to DTT. Every child with ASD is different and requires an individualized approach with a blend of DTT and other intervention methods. Errorless teaching (not letting the child err by using prompts) increases motivation and reinforcement, which in turn increases the rate of acquisition and decreases frustration (Mueller, Palkovic, \& Maynard, 2007). Incidental teaching (teaching skills in the natural environment) uses natural reinforcers and increases the generalization of skills (McGee, Morrier, \& Daly, 1999). Task analyses (breaking a complex skill into individual detailed steps) teach skills such as hand washing or bike riding (Parrott, Schuster, Collins, \& Gassaway, 2000). Functional behavioural assessments (using antecedent and consequence data to determine the function of a behaviour) decrease and increase behaviours (Barnhill, 2005). Using multiple approaches will decrease problematic behaviours, and increase desired behaviours, motivation, communication, and the generalization of skills across domains.

Controversy of ABA. Although ABA has been found to be effective in teaching many children with ASD (Eldevik et al., 2009; Magiati, Charman, \& Howlin, 2007; Makrygianni \& Reed, 2010; Zachor, Ben-Itschak, Rabinovich, \& Lahat, 2007), many advocates of 
neurodiversity fundamentally disagree with ABA programs for children with ASD, as ABA is based on the medical model of disability. ABA programming can focus on normalization with an attempt to cure ASD. Much of the research on the effectiveness of ABA focuses on reducing stereotypical and socially unacceptable behaviours (Nolan \& McBride, 2013). The neurodiversity movement, based on the perspectives of people diagnosed with ASD, argues that ASD is a natural variation or difference, rather than a disorder, and that people have the right to be autistic (Jaarsma \& Welin, 2011; Owren \& Stenhammer, 2013). Person-first language (i.e., person with a disability, as opposed to disabled person) is often adopted by advocates of the social model of disability to avoid defining a person by their disability. Neurodiversity advocates, however, often use the term "autistic" since they argue you cannot separate ASD from the individual (Cascio, 2012).

Outcome measures are often defined in normative terms in ABA research (Nolan \& McBride, 2013), and further research based on the application of ABA in line with the social model is warranted. Particularly, research on the outcome measures for the implementation of ABA in schools that are in line with the social model is needed. The present study aims to investigate $\mathrm{ABA}$ with the social model as a core principle. Using the social model of disability framework, ABA can be used as a teaching methodology without the intent of changing the person and curing ASD, and can be implemented in schools to teach children with ASD, where appropriate.

Effectiveness of ABA. Many studies have assessed the effectiveness of ABA techniques in teaching persons with ASD and have shown it to be a highly effective therapy (Eldevik et al., 2009; Magiati et al., 2007; Makrygianni \& Reed, 2010; Zachor et al., 2007). Makrygianni and Reed (2010) conducted a meta-analysis of 14 peer-reviewed longitudinal studies, focusing on the 
evaluation of behavioural interventions in regard to young children diagnosed with ASD.

Behavioural treatments were found to be more effective in improving intellectual, language, communication, social, and adaptive behavioural abilities in comparison to control non-ABA programs. Overall, increases in intensity, parent training, and duration correlated with increases in intellectual and adaptive behaviour. In relation to the current study, these findings support the use of $\mathrm{ABA}$ in schools, as implementing $\mathrm{ABA}$ in schools extends the duration of therapy. Parent training is likely an important factor since it increases generalization of skills across people and environments. Therefore, it is possible that $\mathrm{ABA}$ in schools promotes the same generalization and increases the effectiveness of ABA.

Zachor et al. (2007) compared two different early intervention programs for children with ASD. Two centres participated in the study; one used an Eclectic-Developmental (ED) approach and one used an $\mathrm{ABA}$ approach. Both programs were based in centres receiving the same amount of funding, enrolling children under three years old, and providing eight hours of service per day. Participants consisted of 19 children with ASD from the ED centre and 20 children with ASD from the ABA centre. The ED programming consisted of special education, speech-language therapy, occupational therapy, music therapy, and structured teaching. ABA programming consisted mainly of individualized DTT, naturalistic teaching, and incidental teaching. Using pre-test/post-test measures with the Autism Diagnostic Observation Schedule (a semi-structured assessment involving interactions between the researcher and participant to assess social and communication functioning), the Bayley Scales of Infant Development (used to assess cognitive ability in preverbal children), and the Stanford-Binet Intelligence Scale (used to assess cognitive ability in verbal children) results showed progress in social interaction, with greater effects in the ABA participants. Significant language and communication progress was seen only in the ABA 
group. These results suggest the benefits of implementing $\mathrm{ABA}$ in the classroom as opposed to an ED approach.

Intensive Behavioural Intervention (IBI), the intensive delivery of ABA, was developed by Lovaas (1987). In his study, 20 children with ASD, aged 5 to 12, were divided into three groups. The first group received 40 hours of IBI every week. The second group received 10 hours of IBI along with other therapies such as special education classes. The third group received no behavioural treatment at all. Results showed that those who received IBI for two or more years had an average gain of 30 IQ points, compared to the two control groups who had no IQ gains. In the group that received the 40 hours of IBI a week, $47 \%$ achieved "normative functioning" (an average level of IQ and were able to go to a mainstream school), 40\% made substantial progress but still had some language difficulties or intellectual disability, and $10 \%$ made little or no progress at all. Although this study provides support for the effectiveness of IBI, it failed to report data for behaviours and language, and based the findings on IQ scores. Research has shown limitations associated with using IQ scores, such as cultural bias, ambiguity in classification of intelligence, motivation, language, test-taking abilities, and compliance (Neisser, 1997). For example, increases in IQ scores may be attributed to an increase in compliance, as opposed to Lovaas' conclusions of increased cognitive ability. An increase in compliance, however, is still an important prerequisite skill for learning.

Despite the limitations of Lovaas' (1987) study, other research illustrates the effects of IBI on the acquisition of skills. Healy, Kenny, Leader, and O'Connor's (2008) case study of a child receiving 32.5 hours of IBI a week for three years showed significant gains across language, behavioural, social and academic domains. Her cognitive skills were assessed by a psychologist a year and a half into the therapy as having a "moderate to severe cognitive deficit" 
(p. 11). By the end of the three years they were assessed and reported to be in the "average range" (p. 11). This change may not necessarily reflect an increase in cognitive ability, but may be attributed to motivation, language, test-taking abilities, and compliance as previously described by Neisser (1997). The child attended general education classes without additional support. Although these results are not generalizable to all children with ASD, this provides an example of the possible benefits of behavioural intervention.

ABA in the classroom. Principles of ABA can be applied to help children with ASD focus, and increase their motivation to complete tasks. Children with ASD, however, often have difficulty learning skills naturally from their environment and need to be taught in an explicit manner. ABA takes complex tasks and breaks them down into small, simple steps. Individual steps are reinforced and mastered before new ones are taught (Whitaker, 2007). Koegel, MatosFreden, Lang, and Koegel (2012) summarize and recommend evidence-based interventions using principles of ABA that can be applied in inclusive classrooms by teachers or support staff. Goals of the interventions focus on communication, challenging behaviour, and socialization. Using a synthesis of previous research, Koegel et al. (2012) recommend the following principles of ABA. Functional behavioural assessments (using antecedent and consequence data to determine the function of a behaviour) can be used to increase and decrease behaviours (Barnhill, 2005). Picture Exchange Communication System (PECS) (a form of augmentative communication where the child uses pictures to communicate) can be used to increase communication (CharlopChristy, Carpente, Le, LeBlanc, \& Kellet, 2002). Prompts (verbal or visual cues to evoke certain behaviours) can assist in independence and errorless teaching, as well as reduce frustration and problematic behaviours (Mueller et al., 2007). Systems of reinforcement (consequences that increase the chance of a behaviour occurring again in the future) should be appropriately applied 
to suit the individual child (Hayward et al., 2009). This recommendation of applying techniques that suit the individual child is known as differentiation, an inclusive educational concept of teaching and adapting to meet individual needs (Evans \& Waring, 2011). This is a central concept of implementing $\mathrm{ABA}$, as individualization is integral in $\mathrm{ABA}$ programming, including the goals, reinforcement, and behaviour protocols (Dunlap, Kern, \& Worcester, 2001).

To assess the effectiveness of ABA as a teaching method in the classroom, Adcock and Cuvo (2008) conducted a study with three children with ASD who were fully integrated into inclusive classrooms, but having great difficulty with select academic subjects, such as reading, math, and grammar; and behavioural domains such as listening to instruction and following directions. Each student was taught using interspersed tasks, prompting, and systematic reinforcement across multiple academic subjects. Using a multiple baseline design, which staggers the interventions, the acquisition in the academic subjects of all three children significantly increased. Although this study uses a small sample, it is evidence that it is possible for behavioural techniques to be implemented and successful in inclusive classrooms.

One limitation of Adcock and Cuvo's study (2008) is that the researchers implemented the interventions. The researcher was likely knowledgeable and trained in ABA, whereas many classroom teachers are not. Also, the researcher implemented the intervention in a one-to-one manner, which is not as feasible in a classroom environment. Other research, however, describes teacher training for $\mathrm{ABA}$. Teachers reported that $\mathrm{ABA}$ the techniques they learned in training are relatively easy to implement in the classroom setting and that they would use these techniques again in the future (Berg et al., 2007). Teacher training packages have been found to be effective in training teachers to implement principles of ABA in the classroom (Grey, Honan, McClean, \& Daly, 2005; Weinkauf, Zeug, Anderson, \& Ala'i-Rosale, 2010) and lead to increased learning 
opportunities for children with ASD (Huskens, Reijers, \& Didden, 2012). Methods have even included web-based consultation for collaboration between behaviour analysts and teachers (Frieder, Peterson, Woodward, Crane, \& Garner, 2009) and games to teach behaviour management techniques (Lowdermilk, Martinez, Pecina, \& Beccera, 2012).

\section{Inclusion}

Inclusion is a process which involves modifications in content, classroom structure, teaching methods, and teaching strategies in order to account for individual differences and support the learning and participation of all children (UNESCO, 2005). Universal design and differentiation are both concepts that are used in inclusive practices. Universal design is the practice of setting up a classroom with the least number of barriers from the outset. It involves knowing the individual needs of children and embedding strategies that work for the largest number of children from the outset. It allows educators to use strategies that may have been designed for a particular subgroup of children, like ABA, with the whole group, for the benefit of the whole group (Jimenez, Graf, \& Rose, 2007). Differentiation is the adaptation of educational activities and teaching techniques to involve individual students' interests, skill levels, and goals in order to support each child in the class (Evans \& Waring, 2011). With differentiation, the teacher may use some strategies with a small sub-set of children that are not appropriate for the whole group. However if universal design has been implemented the teacher will have time to do differentiation. These two concepts have similar outcome goals. However these concepts also differ, as universal design focuses on a group of students (Jimenez, Graf, \& Rose, 2007) whereas differentiation focuses on individual students (Evans \& Waring, 2011). Changes in teaching strategies in inclusive practices can include the implementation of ABA, which can specifically increase the inclusion of children with ASD. According to the social model of disability, 
ineffective teaching methods are barriers to learning and participation, and if $\mathrm{ABA}$ is effective for a child, implementation will remove these barriers.

Benefits of inclusion. In Ontario, there are a variety of options for the placement of children with disabilities. A child can be placed in a regular education class, with varying levels of support, a special education class, or a combination of the two (Ontario Education Act, regulation 181/98). When children with disabilities are placed in segregated special education classes, it is often due to a belief that a regular class with "appropriate special education services" and extra support would not meet the child's needs (Ontario Education Act, regulation 181/98). Inclusive classrooms are ones in which all students are full participants. This is in contrast to regular education classrooms, where children with disabilities may be placed if they can function and learn in the classroom with minimal support, modifications, and accommodations (Fisher, Roach, \& Frey, 2002). Regular education classrooms are based on a medical model of disability, and because full accommodations are not made they do not align with a children's rights perspective

Research shows, however, that children benefit from being in inclusive classrooms (Hauser-Cram, Bronson, \& Upshur, 1993). Ruijs and Peetsma (2008) reviewed studies focusing on the impact that inclusion has on the academic and socio-emotional development of students with disabilities and without disabilities. International studies since 1999 which met the inclusion criteria of a control group of pre-test/post-test of children with mild to moderate disabilities were included. Types of disabilities were not specifically reported; however, children with behavioural, psychosocial, and learning disabilities, which are common characteristics of ASD, were included. Results of the review showed that inclusion has slightly positive effects on the academic development of both children with disabilities and on children without disabilities. 
Kalambouka, Farrell, Dyson, and Kaplan (2007) conducted a systematic literature review to investigate the impact of inclusion on students without disabilities. Twenty-six studies met the inclusion criteria of being empirical research, using longitudinal or comparison studies, and focusing on the education of children from the ages of 5 to 16 . The overall results indicated that the academic and social impact of inclusion on peers without disabilities is usually positive or neutral. This is similar to other research which has shown that children without disabilities in an inclusive classroom with peers with ASD developed typically over the course of the program, in areas of cognitive skills, language skills, and social communication (Stahmer \& Carter, 2005).

The societal benefits of inclusion have also been shown, as Sirlopu et al. (2008) compared students' attitudes towards people with Down syndrome in inclusive schools and noninclusive schools. Using multiple scales adapted from previous studies to measure attitudes, stereotypes, prejudice, affect, trust, and anxiety towards people with Down syndrome, findings suggested that students in inclusive schools had more positive views than students in noninclusive schools. These findings illustrate the potential of teaching children about disability from a young age, as a lack of early exposure to may result in more negative perceptions of people with disabilities (Esmail, Darry, Walter, \& Knupp, 2010).

Factors affecting inclusion. Using research from three case studies, Purdue (2009) investigated facilitators and barriers to successful inclusion of children with disabilities in early childhood environments. One case study used data from a professional development workshop attended by early childhood teachers, other professionals, and parents. Participants provided information about inclusion and their own perspectives of the issues. The other two case studies used data from participant observation in early childhood settings over a ten month period, as well as interviews with teachers, professionals, and parents. Purdue found understandings, 
policies, practices, and resources to be the main factors in successful inclusion. These findings are similar to other research which has found organizational, attitudinal, and knowledge factors to be the main barriers to inclusion (Kochhar \& West, 1996).

Organizational factors refer to the structure of the school and classroom, instructional delivery and classroom management (Kochhar \& West, 1996). Purdue (2009) found that some parents reported inclusion policies as beneficial, as schools or childcare centres could not turn their child away, and in these cases policy acted as a facilitator to inclusion. Other parents, however, reported that policies were so strict that they did not allow room for flexibility, which acted as a barrier to inclusion since they had to fit in with the policy or find another centre. Purdue also stated that inclusion was greater when more resources, such as funding and staffing, were available.

Attitudinal factors refer to teachers' beliefs about disability and inclusion (Kochhar \& West, 1996). Purdue (2009) found that understandings of disabilities impacted professionals' views of inclusion. When a teacher viewed children with disabilities as very different from their peers, this was a barrier to inclusion as they often believed that these children would be better served elsewhere, such as in a segregated classroom with specially trained teachers and professionals. They did not see the education of children with disabilities as their responsibility, which is a barrier to the educational and social inclusion of the child.

Knowledge factors refer to the knowledge and training of teachers in regard to inclusive curriculum and working with children with disabilities (Kochhar \& West, 1996). Purdue (2009) found practices used to include children with disabilities had a large impact on the quality of inclusion. Teachers who did not know how to include children with disabilities often relied on support staff to work with them. This removed the responsibility from themselves and negatively 
impacted inclusion. On the other hand, teachers who used a variety of practices that successfully supported children with disabilities increased the inclusiveness of their classroom. These results illustrate that when a teacher is trained and knowledgeable in working with children with disabilities, the children are included in the class. An implication of this finding is that if a teacher implements principles of $\mathrm{ABA}$ where appropriate when teaching children with ASD, they are more likely to be included in the class.

These themes outlined in Purdue (2009) and Kochhar and West (1996) are similar to those found in further literature on factors affecting inclusion. For example, as research has shown the effectiveness of $\mathrm{ABA}$, many educators are not trained to practice it and have varying degrees of knowledge of the subject (Horrocks, White, \& Roberts, 2008). Some teachers feel they are not capable or equipped to meet the academic, behavioural, and social needs of children with ASD (Horrocks et al., 2008).

Kosmerl (2011) used the Autism Attitude Scale for Teachers (AAST) to determine 50 general education teachers' and 50 special education teachers' feelings towards the inclusion of children with ASD. Most teachers were receptive to inclusion, with special education teachers being more receptive than general education teachers. Some teachers, however, reported that it was "unfair" to have children with ASD in their classroom without proper support and training. Through follow-up interview questions, general education teachers also discussed the supports they would need in an inclusive classroom. Supports included a general care assistant, training for ASD, and access to an ASD consultant. Special education teachers reported they could support general educators by consulting with them for IEPs, sharing special resources, and assisting with behaviour assessments and behaviour plans. Thus, collaboration and training 
emerged as factors that impacted teachers' feelings towards inclusion. Teachers were open to the idea of inclusion; however felt they were not receiving the needed support.

Downing, Ryndak, and Clark (2000) investigated the perspectives of teaching assistants who work with children with moderate to severe disabilities in inclusive classrooms. Teaching assistants reported the importance of collaboration with the team (teacher, special educator, etc.), but were involved in varying degrees of collaboration. The most striking finding in this study was that although knowledge impacts teaching (Cologon, 2012), most teaching assistants had received no training when first hired, although they are the ones who spent the most time with the children. This study took place in the United States, and generalization of these findings to Ontario schools is possible but cannot be assumed. If this is the case with teaching assistants in Ontario as well, then PPM 140 will not be successful as proper knowledge and training is imperative to the implementation of ABA.

Bose and Hinojosa (2008) interviewed 6 occupational therapists (OTs) working in inclusive classrooms about their perceptions of collaboration. All the OTs valued collaboration, but reported that it did not take place due to time and scheduling constraints and noted varying degrees of teacher receptiveness to their suggestions. This article highlights an important issue of contrasting teaching methods, possibly for reasons such as conflicting values and experiences, and a lack of understanding of the field. Teachers are not behaviour therapists, and it is understandable that they are not fully trained in ABA since this is not the focus of their job. However, research and practice from outside fields such as ABA, are adopted at times in order to be inclusive.

When teachers were receptive to their suggestions, OTs attributed positive characteristics to them and described them as "good teachers" (Bose \& Hinojosa, 2008, p. 293), whereas 
teachers who were thought of as unreceptive were described as "apathetic" (Bose \& Hinojosa, 2008, p. 293). This highlights the topic of attributions between professionals, particularly an attribution error. The OTs were making internal attributions about the behaviours of teachers, since they blamed the teachers' dispositions as opposed to taking into account other external circumstances. The significance of attribution theory in this case is in regard to collaboration between professionals.

To summarize, research suggests that organizational, attitudinal, knowledge (Kochhar \& West, 1996; Purdue, 2009), and collaboration factors (Bose \& Hinojosa, 2008; Downing et al., 2000) affect an inclusive environment. Organizational factors, such as structure of the school and classroom, policy, and resources, affect teachers' ability to create an inclusive environment (Kochhar \& West, 1996). Attitudinal factors, such as beliefs about disability and inclusion, impact how professionals view and practice inclusion. Those who view children with disabilities as different tend to engage in less inclusive practices (Purdue, 2009). Knowledge factors, such as the education and training of professionals, impact teachers' ability to teach children with disabilities as well as their view of the roles and responsibility of professionals in the classroom (Purdue, 2009). Collaboration between all professionals involved with the child has been found to be an important factor in integrating various teaching methods (Bose \& Hinojosa, 2008; Downing et al., 2000). The present study focuses on the factors that affect the inclusion of children with ASD, specifically by investigating the factors that affect the implementation of ABA.

\section{Research Question}

This literature review has outlined the effectiveness of ABA, and despite the controversy sparked by the neurodiversity movement, ABA can be used as an effective teaching method for 
some children with ASD. Using a social model of disability lens, the implementation of ABA can remove barriers to the education and inclusion of these children. Children with ASD benefit socially and academically from inclusion, and ABA may be an integral part to the effective inclusion of children with ASD. It is therefore within the children's rights to receive ABA in schools. There are over 10,000 children with ASD in the Ontario school system (Ontario Ministry of Education, 2011), and PPM 140 may benefit these children socially and academically. In order for the policy to be successful, ABA must be successfully and effectively implemented, and the factors that impact the implementation of ABA in schools must be investigated. The present study will do so by answering the following research question: what are the facilitators and barriers to effective implementation of $\mathrm{ABA}$ in schools? 


\section{Chapter 3: Method}

The purpose of this study is to investigate the facilitators and barriers to implementation of ABA in schools. Qualitative designs are used to understand and explore social phenomena (Marvasti, 2004). The present study uses a qualitative design to gain insight into behaviour therapists' perceptions and experiences of the application of ABA in schools. This section outlines the participants, research design, recruitment process, setting, data collection, data analysis, and the researcher characteristics with regard to the present study.

\section{Participants}

Participants consisted of four behaviour therapists. Behaviour therapists provide ABA therapy to children with ASD in a variety of settings, such as behavioural treatment centres, homes, communities, and schools. As this was an exploratory study, a manageable number of participants who could provide a range of understandings which could be investigated in depth were needed. The selection criterion for behaviour therapists was they must have worked with a child with ASD in a kindergarten to grade four classroom in an elementary school in Ontario. Behaviour therapists go into schools to work with children with ASD and, at times, consult with teachers about how to implement ABA in the classroom. Therefore, they face many facilitators and barriers to effective implementation of $\mathrm{ABA}$ in schools and can provide insight to the research question.

Behaviour therapists work either independently or for agencies. They are hired by parents, as opposed to the school board, to work directly with children with ASD and at times provide child-specific consultation to teachers. As they are employees of the parents, either independently or through private or public organizations, rather than the school board, behaviour therapists are constrained in their role in the classroom and restricted in the input that they can 
provide to classroom programming and structure. This is an integral difference between behaviour therapists and other professionals, such as ASD consultants, as well as psychologists, speech-language pathologists, and resource consultants. A limitation of the sample is that other professionals are not included in the study. The recruitment strategy for the study included teachers and ASD consultants at the outset. However, due to timing of the study and the lengthy procedures to receive ethical approval, the recruitment for the study began in June. At that time, it was not possible to recruit the required number of teachers for the study. ASD consultants, who are implementing PPM 140 in schools, were not able to participate in the study as ethical approval was not received from the regional ABA service provider. Therefore, as teachers and ASD consultants could not be recruited, the study focuses on the perceptions and experiences of behaviour therapists who work either independently with parents, with private organizations, or public organizations. . They work one-on-one with the children, and implement child-specific ABA techniques. They have experience with the same children in different environments, and are able to compare child-specific implementation of ABA in a clinical setting to a school setting. When working in schools, behaviour therapists work with a specific child and, at times, provide the teacher with information and suggestions for working with the child. In this role, they are able to provide a rich insight into the facilitators and barriers to implementation of ABA in classrooms.

\section{Design}

Individual interviews were conducted to explore the perceptions and experiences of participants in implementing ABA in the classroom (see Appendix A for interview protocol). Semi-structured interviews consisted of predetermined questions which provided an opportunity for participants to voice their own experiences and perspectives in their own words (DiCicco- 
Bloom \& Crabtree, 2006). Questions about the behaviour therapists' roles and experiences in the school were asked to provide context for the interview and to gain an understanding of the participants' individual perspectives about implementing ABA in the classroom. Participants were then asked about their perceptions of the feasibility of ABA in the classroom, as well as particular strategies they have implemented. This was followed by questions about teachers' implementation of $\mathrm{ABA}$, receptiveness, and the environment of the classroom. Questions about support and communication with the teachers were included as these have been found in the literature to be barriers to inclusion (Bose \& Hinojosa, 2008; Downing et al., 2000; Kochhar \& West, 1996; Purdue, 2009). Then, participants were asked what they believed were the main facilitators and barriers to implementation of ABA.

When participants provided answers to questions that the researcher did not anticipate, the researcher probed with further questions that explored those topics in greater depth (Roulston, 2011). After an initial analysis of the interview data, follow-up structured questionnaires (Kazi \& Khalid, 2012) were emailed to participants to further probe their responses and to increase the clarity and depth of data. This iterative process is similar to a grounded theory design in that collection and analysis occurred simultaneously (Corbin \& Strauss, 1990). In the present study, the data from the interviews was collected and analyzed, and as themes emerged from the interviews, they shaped the questions asked in the follow-up questionnaires. For example, the theme of tolerance for problem behaviours arose. Therefore the questionnaire asked participants about specific problem behaviours, and who defines behaviours as problematic. Then data from the questionnaires was analyzed and incorporated into the existing themes. A main difference between grounded theory and the present study is that in grounded theory theoretical saturation of a social phenomenon is obtained (Corbin \& Strauss, 
1990). Theoretical saturation is reached when new data no longer results in greater depth of themes (Charmaz, 2008). Complete theoretical saturation was not reached in the present study, since more data and analyses would be needed to acquire such depth and provide evidence for theoretical saturation (Charmaz, 2008).

The structured design of the follow-up questionnaire meant that each participant received nine pre-determined, open-ended questions (see Appendix B for follow-up questionnaire). These follow-up questions were probing questions based on information that was missing from the participants' interview answers (DiCicco-Bloom \& Crabtree, 2006). In the interviews, participants discussed problem behaviours that are targeted for ABA intervention in the schools. Participants were asked in the follow-up to specify what these problem behaviours are, how teachers define problem behaviours, how behaviour therapists define problem behaviours, and how these behaviours affect those in the classroom. In the interviews, several participants discussed ABA knowledge and principles, as well as training needs for teachers. Participants were asked in the follow-up to explain specifically what $\mathrm{ABA}$ principles they thought needed to be articulated more clearly for teachers. Additionally, therapists identified training as a need for teachers in the interview and were asked to clarify training needs for teachers. In the interviews, several participants stated that ABA can be implemented in classrooms. Participants were asked in the follow-up to expand on ideal roles of different professionals in the classrooms when implementing ABA. They were also asked how they could see their role expand to contribute more in the classroom, and how ABA can help to achieve the goals of the classroom.

\section{Recruitment}

To recruit behaviour therapists, the researcher sent a recruitment email to previous professional contacts in the field (see Appendix $\mathrm{C}$ for recruitment email). These colleagues 
forwarded the recruitment email to their own networks of behaviour therapists. This form of sampling, known as snowball sampling, is often used to conduct research with difficult to reach populations (Goodman, 1961). Based on the sampling attempts with teachers and ASD consultants, this population was deemed difficult to reach. Although snowball sampling may result in a relatively homogeneous group of behaviour therapists (Ravitch \& Riggan, 2012) with regard to education and experience, the researcher contacted multiple colleagues to ensure participants were not recruited from a single source, but from different ABA service providers. Individuals interested in participating in the study contacted the researcher via email. The researcher responded to participants' questions and arranged a time and place for interviews. A copy of the informed consent was attached to the email for participants' records (see Appendix D for consent form). Informed consent was obtained from participants prior to the onset of data collection.

\section{Setting}

Interviews took place in locations that were convenient for the participants. If no personal preference was mentioned, a private seminar room at Ryerson University or a local public library was offered to ensure confidentiality and convenience for the participants. The researcher travelled to the participants' preferred location. Locations consisted of two public libraries and two coffee shops.

\section{Data Collection}

Interviews ranged from 10 minutes to 30 minutes, with an average length of 20 minutes. The main interview questions pertained to participants' knowledge of, perceptions of, experiences with, perceived challenges/barriers to, resources for, effectiveness of, $\mathrm{ABA}$ in school settings. Participation in the study was voluntary and no identifying information was recorded, 
and pseudonyms were used to ensure confidentiality. Ethical approval was received from Ryerson University. Participants were reminded that they did not have to answer any questions that they did not feel comfortable with and that they could stop participation at any time. With participants consent, interviews were audio-recorded and transcribed, with no identifying information attached. Only the researcher and the researcher's supervisors had access to the data. All data (recordings and transcriptions) were stored on a password protected data key for transportation, and then on a password protected computer.

After initial analysis of the interview data, follow-up questionnaires were emailed to participants to obtain clarification and more information about some of the responses. Participants were told that participation in the follow-up was not a requirement based on initial participation in the interviews. The questionnaires allowed for a deeper level of thematic analysis. A list of nine questions was emailed to all four participants, all of which were completed and returned.

\section{Data Organization and Analysis}

Once all interviews were transcribed, a thematic analysis of interviews (Braun \& Clarke, 2006) was used to code the facilitators and barriers to implementation of ABA in schools. Thematic analysis is a method used in qualitative research to identify and analyze common themes across data (Gibson \& Brown, 2009). Themes are patterns in the data which represent meaning (Braun \& Clarke, 2006) and were discovered using the process of thematic analysis outlined by Braun and Clarke.

To begin, each interview was transcribed by the researcher. Transcripts were read and reread as the researcher reflected on the data and began a list of initial concepts in the data. Initial codes were then generated from these concepts. Codes included themes found in the literature, 
(Creswell, 2009) as well as common themes across interviews (Gibson \& Brown, 2009). Themes were reviewed, and some were collapsed into one theme while others were separated into multiple themes. To increase the clarity and depth of themes, responses from the follow-up questionnaires were analyzed using the coding structure derived from analysis of the interview data, and integrated into the findings. Once the final themes were complete, they were defined and named to ensure they captured what the data represented (Braun \& Clarke, 2006).

\section{Researcher Characteristics}

Qualitative research is assumed to contain a certain degree of researcher subjectivity and bias as it is impossible for the researcher to remain completely objective (Mehra, 2002). The researcher of the present study has professional experience in the field of $\mathrm{ABA}$ and this impacted the study in different ways. The researcher's experience in the field guided the research question, and the researcher's knowledge assisted with an in-depth understanding of the topic and spontaneous follow-up or probing questions during the interviews. However, this experience presented some bias as the creation of knowledge comes from the researcher's interactions during the study process (Mehra, 2002). This was recognized and reflected upon throughout the research process and during data analysis. 


\section{Chapter 4: Findings}

Five main themes that emerged from the thematic analysis are supported in this section by quotes from interview and questionnaire data. Participant characteristics are outlined to provide context for their perceptions and experiences. All participants reported that, in their experiences working in schools, ABA is rarely, if ever, implemented. Participants discussed their experiences of working in schools, and provided their perceptions on the facilitators and barriers that affect the implementation of ABA in schools.

\section{Participant Characteristics}

Four behaviour therapists participated in the study, and the following pseudonyms were used: Alison, Brian, Carolyn, and Diane. All participants work or have worked with children with ASD, implementing ABA in an ABA centre, the child's home, childcare settings, schools, and community settings in the Greater Toronto Area. ABA centres are clinical settings; they are designed to be conducive to implementing ABA. Alison has been a behaviour therapist for seven years, and works as a senior behaviour therapist for a small, privately owned ABA centre. On a daily basis, she implements ABA with children with ASD. On top of this, her role as a senior behaviour therapist consists of meeting with parents in regard to $\mathrm{ABA}$, planning individualized ABA programs, supervising and training other behaviour therapists, as well as attending some school meetings, and discussing child-specific ABA techniques with teachers. Brian has been a behaviour therapist for approximately 10 years, working both privately and for a small, privately owned ABA centre. His role as a behaviour therapist consists of implementing ABA with children with ASD, with a focus on recreation and life skills. Carolyn previously worked as a behaviour therapist for seven years in a large, publicly funded ABA centre. She implemented ABA therapy on a daily basis, and spent part of this time as a senior behaviour therapist, where 
she met with parents and planned individualized ABA programs. Diane has been a behaviour therapist for approximately three and a half years, working for a variety of privately and publicly funded ABA centres, implementing ABA with children with ASD. This range of experiences informs the participants understanding of school-based ABA intervention, and gives them a comparative lens for understanding $\mathrm{ABA}$ in schools and in other settings.

\section{Thematic Analysis of Interview Data}

A thematic analysis of participants' responses to interview questions and follow-up questionnaires produced five main themes that will be presented in this section. The main themes are: 1) reinforcement in the classroom; 2) consistency; 3) ABA and behaviours in the classroom; 4) collaboration; and 5) attributions. The use of reinforcement in the classroom was reported as an integral principle of ABA. The consistency of implementation is perceived to be lacking, as is consistency of expectations in and across children's environments. Varying definitions of problem behaviours in the classroom were reported, along with a certain level of tolerance for some behaviours and their corresponding behaviour protocols. Participants discussed how ABA can be effectively implemented with the support of collaboration between professionals. Participants also discussed to what they attribute the cause of barriers to implementation of ABA. These themes were reflected in all four participants' responses across both interview and questionnaire data, and across questions in both data collection methods. The source of each quote is identified in brackets, as either interview or questionnaire data. All quotes are verbatim, except when edited for readability. It should be noted that quotes reflect the perception of behaviour therapists, and may not reflect the perceptions of teachers or other professionals.

\section{Reinforcement in the Classroom}


All participants discussed the importance of reinforcement in the classroom along with their beliefs that it is often improperly implemented within the classroom. All participants stated that reinforcement is one of the most important principles of ABA to be implemented in the classroom. They communicated that in order to properly and effectively implement reinforcement the concept must be understood by teachers. Participants expressed concern with how the value of reinforcement is perceived by teachers, as well as how reinforcement is accepted and implemented in the classroom. To illustrate, Alison (interview) stated, "It's your knowledge of why you're doing things...to understand what reinforcement means and why you do it and when you do it and that it has to be immediate." Brian (questionnaire) reported that "teachers need to understand extinction [ignoring a behaviour] more clearly. They need to understand functions of behaviours to make sure they are not reinforcing it."

Alison (questionnaire) explained how this understanding of reinforcement is important, since there are times when it seems unnatural:

I would say that reinforcement is the most important principle to understand. When a child has a problem behaviour within the classroom, teachers feel the need to end that behaviour through removing the child from the classroom or a punishment. The idea of reinforcing desired behaviours is not as natural, primarily because this does not provide the teacher with negative reinforcement, the way that the former strategy would. Alison (interview) provided an example of how without this understanding of reinforcement, it is difficult to see the value of continuing the reinforcement:

They [the teacher] had seen huge successes in the child, and maybe without the full understanding that the reinforcement system done properly was the reason for that 
success. And so, they were sort of at the point where they didn't feel it was necessary anymore. Even though it was.

When the value of the reinforcement is not understood, teachers may opt for other consequences, which subsequently reinforce a behaviour they want do not want to reinforce. Carolyn (interview) provided an example of a teacher inadvertently reinforcing what they felt was a problem behaviour:

When it comes to handling behaviours, teachers will treat them [children with ASD] like a typical child. I see that all the time. A child [with ASD] does something negative, and automatically the teacher comes in and she's attending. She's talking about it, explaining why you shouldn't do that. And a typical child would understand, like “ok, I'm in trouble. I did this. It hurts people and I shouldn't do this again”. You can reason with a typical child. But with children with ASD, for the two seconds it seems like he or she understands but all you're doing is providing that attention and that's what they want. They're seeking that attention.

Carolyn (interview) also explained the results of inadvertently reinforcing behaviours.

Reinforcement seems to be difficult [to implement in classrooms]... Or if there's a procedure to ignore, you know differentially reinforce, so like ignore a particular behaviour and reinforce another, that doesn't seem to ever really happen.

Two participants discussed how types of reinforcement were accepted when they were working in a classroom and how they experienced varying degrees of accepted types of reinforcement. Diane reported that teachers were sometimes supportive of the reinforcement, but their acceptance depended on the type of reinforcement, "I was able to reinforce, the teachers 
sometimes were supportive with it. I mean you couldn't always give edibles like you do when doing one-to-one, but you have to find other ways to provide that."

Carolyn (interview), on the other hand, provided an experience of being able to use a preferred type of reinforcement in the classroom, "I think they're ok with the reinforcement system. Like I was using like edibles cause he was on a very thick schedule so I had to reinforce him very, very often. So they were ok with that."

\section{Consistency}

Participants discussed the issue of reinforcement systems not always being consistently implemented within the classroom as well as across environments, such as schools, ABA centres, and home. Separate from reinforcement, the variation of expectations of behaviours and schedules was also discussed across these environments.

The consistency and inconsistency of reinforcement was discussed by participants 1,2 , and 3 as an issue within classrooms as well as across environments. Alison (interview) explained how reinforcement systems are initially effective, however due to a lack of consistency with in the classroom the effects are only short-term:

Any reinforcement system I put in, be it a point system or tokens or whatever, never seems to get fully implemented. The first little bit does and then they [teachers] see the improvement and then it drops off. Then we see those behaviours again, and then there's sort of a feeling that it doesn't work. But it doesn't work unless you're doing it consistently and properly.

Reinforcement was reported to also be inconsistently implemented across environments. Carolyn (interview) explained an inconsistency in the application of reinforcement between the school and the ABA centre where she works: 
I was working with a kid the other day and he has a lot of behaviours and we have a protocol that we follow at our $[\mathrm{ABA}]$ centre, but we have to be consistent with a protocol and it's very difficult to do that in a different environment. For instance, his behaviour was like, a lot of tantrumming, a lot of attention seeking behaviours, so the protocol is to ignore. When you go to a classroom the teacher doesn't really allow this behaviour to be ignored. She addresses right away. And this really clashes with what we've been taught or what we're asked to do.

The result of this issue is that changes need to be made that are not in line with the principles of ABA. Carolyn explained:

So we actually had to modify our protocol, just so it's consistent across environments... And we only had to do that so that we could do the same thing at school. But that's where I mean, it's going against what we believe [principles of $A B A$ ] in just so we can actually be consistent with all environments.

Apart from the consistency of reinforcement, participants also reported a general inconsistency within and across environments. Carolyn (interview) explained an inconsistency within the classroom, between what she implemented with the child and what a teacher implemented with the child, "I'm doing one thing and then I see her [teacher] doing almost the opposite thing."

Inconsistency across environments included schools, ABA centres, and the child's home. Carolyn (interview) reported inconsistency across all three:

We're running it one way and then he goes to school and things are totally different. And then at home it's another environment. There's so much inconsistency going around in that one child's, you know in different environments. 
Alison (interview) compared the consistency in an ABA centre to the consistency in schools, and explained the result of such inconsistency and how it affects the child's learning:

There's predictability in an ABA centre, in schools there's not always, even if there's schedules and things like that they're maybe not using them. Um, that's one thing I see, like you see a lot of the materials and a lot of the ideas there, but nothings really being implemented properly so it's not really working. So the kid can't engage with it the way that they know how to. Unless it's such a deeply ingrained mastered skill that they've been able to generalize it.

\section{ABA and Behaviours in the Classroom}

Another theme that emerged from the data was that of behaviours in the classroom. There was a variation of definitions of problem behaviours between participants as well as teachers, such as behaviours that are disruptive, harmful, non-compliant, and socially unacceptable. Eradication of these problem behaviours were often the reported goal of bringing ABA into the classroom, however, as behaviours become disruptive there appeared to be a low level of tolerance for some behaviours and $\mathrm{ABA}$ techniques.

The definition of problem behaviours showed some variation between participants. Alison (questionnaire) defined problem behaviours as ones that interfere with learning or cause safety concerns:

behaviours that interfere with learning, such as crying when going back to work or "stimming" that reduces attention, that are harmful to oneself or to others (such as biting ones arm or scratching another person), or that cause safety concerns.

Brian (questionnaire) defined problem behaviours as mainly aggressive ones such as, "spitting, kicking, fighting, urinating in pants, crying, screaming, hitting, biting”. While Carolyn 
(questionnaire) mentioned behaviours that are disruptive, her focus was on behaviours that are often deemed socially unacceptable. She defined problem behaviours as, "socially inappropriate behaviours such as stimming, scripting, and disruptive behaviours".

Participants provided definitions of what they believe teachers define as problem behaviours, as these are the behaviours that are often focused on in the classroom. There was some variation of responses, however, these definitions focused on non-compliance and behaviours that are disruptive to the class. Alison (questionnaire) reported that teachers define problem behaviours to be, "Generally anything that is disruptive in their classroom, such as loud noises, non-compliance, tantrums, etc. Learning and social concerns are rarely present”.

Carolyn (questionnaire) reported that teachers define problem behaviours as, "any disruptive behaviours... such as screaming, hitting, flopping”. Diane (questionnaire) reported that teachers define problem behaviours as, "Non-compliance. When a teacher gives an instruction and the child doesn't attend or "perform". For example, come to circle, line up, put your hand up, quiet please".

All four participants reported that the most common reason for them to work with children with ASD in classrooms is for behavioural reasons, generally as defined by teachers. Participants reported that, in their experiences, the goal of ABA in the classroom is to focus on decreasing problem behaviours, as defined by teachers, as well as increasing behaviours such as following directions. For example, Diane (interview) stated the reasons for her being in the school as, "Making sure the kids follow the classroom routine and follow teachers' instructions". Alison (interview) also provided a similar response: 
The issues surrounding them [students] were primarily behavioural. Behavioural and negative behaviours but also just the behaviour of being able to sit on the carpet and follow classroom routines.

Alison explained how, in her experience, there tends to be a behavioural focus rather than academics or social skills. Alison (interview) stated:

The major thing that I've seen is that there's no learning happening in schools. Whether it's academics or behavioural learning or anything like that, it's what the goals seems to be is keeping the child safe, and to engage in behaviours but there's no acquisition learning from what I've seen.

As participants stated that their main role was to manage behaviours, they discussed that at a certain level, when behaviours increased to a disruptive level, teachers' tolerance to ABA in the classroom decreased. Carolyn (interview) explained how aggressive and disruptive behaviours are often not met with ABA behaviour protocols:

With behaviour protocols I think it's very difficult for them [teachers] to follow. If it comes to a point where the kids behaviour is escalating and it's way too aggressive and it's being disruptive that's when it becomes difficult.

She elaborated (interview):

Because to them [teachers] it's like "ok I have a whole class to deal with and cannot have a kid destroying my things, I need it to stop right away." A lot of the time the teacher complains, "we can't let this happen"... So even though, for instance, it was all attention seeking behaviour so what we had to do is we were basically taking him to a corner, so that's obviously providing attention when we take him to the corner. And the behaviour just escalates to half hour long behaviours. 
Carolyn (interview) explained how attending to an attention seeking behaviour will stop the behaviour at the time. This attention, however, is reinforcing and the behaviour is more likely to occur in the future:

Yes the [attention seeking] behaviour automatically stops when you attend to them. And, it does stop, versus ... when you ignore you don't see it working, because it's escalating to so much where he's spitting, he's kicking things, he's hitting you, and when I attend he stops. And this is what they're [teachers] seeing, and they're seeing your strategy is not working. They're like ok my strategy is so much better, it's working right away it's not getting disruptive. And to them I think that's more important than a long term solution.

\section{Collaboration}

All participants reported that collaboration with others, such as professionals and parents, both in and outside of the classroom is an important factor in effectively implementing ABA. ASD consultants are hired by the school board to provide general ABA consultation to teachers. Participants discussed the importance of such collaboration, as well as what concepts they believe ASD consultants should focus on relaying to teachers. Participants also discussed communication between parents, teachers, and behaviour therapists outside of the classroom, as well as the impact of current policy on collaboration. Collaboration within the classroom focused on professionals working together to support the student. Support was defined as a higher staff to child ratio, or one-to-one support, depending on the needs of the child and the specifics of the implementation of ABA. Participants discussed how without this support some principles of $\mathrm{ABA}$ are difficult to effectively implement, because the teacher does not always have time to attend to one specific child while teaching the entire class. 
Alison, Brian, and Carolyn discussed the importance of ASD consultants teaching teachers about reinforcement and functions of behaviours. Alison (questionnaire) explained what is important for ASD consultants to address with teachers:

Creating and learning how to properly implement reinforcement systems that are conducive in a classroom would be the most important things for ASD consultants to address with teachers.

Diane (questionnaire) reported that it would be beneficial for ASD consultants to teach teachers "to be flexible in terms of incorporating different teaching styles to help all children."

Besides ASD consultants teaching teachers, collaboration between other professionals and their specific roles were discussed. Diane (questionnaire) explained the ideal role of different professionals:

Teachers would be there to implement the lesson. However the [ASD] consultant could work with the teacher in terms of offering support in how to teach these lessons to the child [with ASD]. These strategies don't only help one child, they could actually help several children in the classroom.

The importance of collaboration to support teachers was highlighted by Alison (questionnaire): I think a collaborative approach between teachers, parents, [behaviour] therapists and EAs [educational assistants] is necessary for successful integration of ABA strategies within a classroom. Understanding the principles of behaviours is important but so is realizing that in the implementation phase of them, individualization is required. Consultants should help set up and then maintain (and inevitably adjust) the classroom environment so it is conducive to ABA therapists. The teacher should be leading throughout the day-to-day and supported by EAs to ensure follow through. Parents and 
therapists who know the children the best should bring about the individualization piece.

On a regular basis, all involved should be meeting to assess and adjust.

Alison (questionnaire) specifically reported why she believes such collaboration and support should include the behaviour therapist:

When a child receives funding, a therapist such as myself generally spends years teaching them, creating programming for them and creating behaviour protocols... Without being part of the team with the teacher, it would be difficult to help with the general classroom environment.

Such collaboration was reported to be influenced by policy, as two participants stated that policy plays a role in the collaboration between professionals and at times restricts the roles of the behaviour therapist. When asked about what she perceives are barriers to implementation of $\mathrm{ABA}$ in schools, Carolyn (interview) replied:

Well their policy. A lot of the time some of the schools don't even allow outside [behaviour] therapists to go in. And if they do, they have rules and regulations, they have their schedules and, so we can't really step in and do anything. So you're just there more like observing. And sometimes we're [behaviour therapists] not even allowed to take data.

Alison (interview) stated that it is difficult for a behaviour therapist to enter the school until issues have escalated, "It's sort of at the point where when they [teachers or parents] ask for us to come in things need to be pretty out of hand I guess for them to actually be like, "yeah, come on in and help us out."

Parents were noted by Alison (interview) as playing an important role in initiating ABA support from behaviour therapists and stated, "Usually it has to be prompted by the parent 
because we're hired by the parent we're not hired by the school." When asked about continued communication and opportunities to see follow-through, Alison (interview) replied:

Unless the parent is prompting all of these follow-up visits, no. Usually not unless a new problem pops up or a huge transition's about to happen or something like that. But otherwise, no. But that is usually because we're private and the school wouldn't hire us directly to come. It's really up to the parent.

Because the behaviour therapists are hired by the parent and other organizations, participants reported it is difficult for them to collaborate with teachers at times. Alison (interview) explained more about communication:

That relationship was built because the parent created that team. Unless there's a crisis going on teachers don't generally reach out so much for the basic everyday things. Alison (interview) explained that she believes support from other professionals is an important component of effective ABA implementation.

If you're not able to create interventions on your own, you can't just have someone drop in and say "do this", because the thing about ABA is that we are always looking at the data and we are changing our strategies based on the data. If you don't have someone doing that then there's no way that whatever skills or behaviour you're targeting, you're not going to get to that end point.

Besides collaboration outside of the classroom, collaboration within the classroom was reported by three participants as being a facilitator in implementing ABA. Opportunities for oneto-one support for the student were reported to be essential facilitators for effective implementation of ABA. Participants consistently stated that professionals need to work together as there is not always time for one person (i.e., the teacher) to implement ABA by themselves 
while teaching an entire class. For example, Brian (interview) explained why this extra support is necessary:

It's [implementing ABA] very difficult because they're [teachers] so overwhelmed with other kids. Other kids need stuff from them. It's tough for the teachers to focus on one child.

Diane provided a similar statement:

It's obviously more difficult because there's more kids and you can't really go up to every kid and go "good job, you're doing well." So the only time they [teachers] do give attention is when they [students] do something negative. Like immediately the teacher attends to that kid and the kid is getting reinforced.

Participants explained how with extra support, ABA can be effectively implemented.

When discussing behavioural issues in classrooms, Carolyn (interview) explained how professionals collaborating in the classroom facilitate the implementation of ABA:

They [the teachers] don't really follow any antecedent strategies, because they have to attend to so many kids. But when we're there we're able to do that, to prevent certain behaviours from occurring.

Behavioural or skill acquisition data is collected in $\mathrm{ABA}$ in order to analyze trends in the data, move forward to next steps, and modify procedures. Alison (interview) explained how professionals need to work together at times to obtain this data:

When to know when to move to the next step with things, when to increase the time that the child's sitting on the floor, you sort of need someone focused on that child for a period of time to get that information. 
Alison explained how some principles of ABA can be implemented by the teacher with little support, at times there are too many principles or behaviours for one person to implement. Although she reported that ABA may be difficult to implement, with the proper support she reported that she believes it is possible (interview).

The barrier is just going to be that you'll never be able to catch the good behaviours because you're always going to be implementing a protocol for a different kid. But if there's support in the classroom, like even a couple of EAs then a reinforcement system can be put in for all the kids.

Carolyn (interview) explained how if a child needs a more intensive or frequent application of $\mathrm{ABA}$, this is difficult without collaboration, however, for some children less support and collaboration is needed.

It really depends on the kid and how independent he is and what kind of behaviours he has. If it's a behavioural kid I think it would be very difficult for the teacher to only attend to him. And, at least that's what I've seen. But if it's a kid that is independent, he's able to sit at the desk for $\mathrm{x}$ number of minutes and can get his tasks complete, then I think the teacher can remind herself that after this many minutes I should reinforce.

Brian (interview) explained that when extra staff support is lacking, "There's no one there to support this child, they're not going to get any support whatsoever. They're just going to be left in the back. Sit in the back row and get lost." and "if there's no support in the classroom for the child then it's very difficult for them to have any sort of learning". He also explained when the support for the student is most necessary (interview):

Especially if you're trying to transition a kid out of therapy and into a classroom they need the supports. That's it, they need it. There's no getting around it. They need that 
person like prompting them, you know, little bits, just cause the teacher's not going to do

it. That's just what I've seen in the classroom. They're not going to put the effort in and honestly they don't have the time to because there are so many other things going on in the classroom.

\section{Attributions}

The previous themes were based on participants' observations while working in classrooms. Participants reported that they believe teachers are either incorrectly implementing, or not implementing, ABA strategies when working with children with ASD, and often stated what they attributed to be the cause of the barriers. All participants attributed incorrect or absent implementation of $\mathrm{ABA}$ in classrooms to a lack of teacher knowledge of $\mathrm{ABA}$ and support in the classroom.

All participants reported that they feel that teachers are not knowledgeable in ABA. When discussing principles of ABA, Alison (interview) stated, "Reinforcement seems to be difficult [to implement in classrooms]. I think the major reason is that teachers don't fully understand why the reinforcement is like that." Brian (interview) was asked if he thought teachers have the knowledge, training and understanding of ABA, and replied, “They don't, no. they have no idea. The majority of people I have worked with, none of them do". Carolyn (interview) similarly reported, "I think if they [teachers] were more knowledgeable about what we [behaviour therapists] do, and about our principles it would definitely help... they say that they understand but when actually comes to applying it, I think for them it's difficult”.

All four participants who believe teachers are not knowledgeable in ABA attributed this lack of knowledge to a lack of education and training. Alison also attributed the lack of knowledge on a lack of collaboration between teachers and ASD consultants. Diane (interview) 
stated, "Teachers are not [implementing ABA], and it's not their fault, they're just not being taught." Brian (interview) had a consistent response, "But they [teachers] have no idea how to actually implement it [ABA]. I haven't seen it. They're not really trained on ABA." Carolyn (interview) also stated, "So I think it's just the education, the lack of education the lack of knowledge in that field." Carolyn (interview) went on to say:

Having an education on ABA would definitely help them [teachers]. 'Cause once you understand the principles you will be able to actually, you know, implement it better. Without just someone coming and telling you, do this, do that. If they have a good understanding of how it's [ABA] done and a good understanding of kids with special needs or autism, I think that would really, really help.

One teacher specifically told Alison how she did not have a lot of education on ABA (interview): In the community classrooms the teachers have some courses but I mean for example, the last teacher who I spoke to in a meeting said "you know like I took my special ed. courses but that's all I really know", right? And she's in charge of the community classroom which all children with autism go to.

Diane specifically attributed this lack of education and training to teachers college. Diane (interview) stated, “They [teacher's college] teach about lesson plans, they teach about other things in school, they don't necessarily teach about autism and integration. So that's a huge problem." She went on to say (interview):

I also think in teachers college they should be teaching more about disabilities and autism and $\mathrm{ABA}$. And there should be something 'cause all these kids are being integrated into classrooms, funding's being cut, you're not going to get it forever and then they are going to be going into schools. So teachers need to be ready because they're not allowing ABA 
therapists to come in at this point. A lot of the time we're not allowed in there. So that's a huge problem.

She believes that education in teachers college could provide teachers with the support they need to effectively teach and include students with ASD using ABA (interview):

I think a lot of this stems from when the teachers are in teachers college. Like I think the best way is for them to have a course, a crash course on ABA. I think that's so important. Especially if it is going to go into school systems, you need to know what you're doing. I'm going to teach math, oh, but I need to include ABA. So, how do you do it?

\section{Summary}

A thematic analysis of participants' responses to interview questions and follow-up questionnaires produced five main themes: reinforcement in the classroom, consistency, ABA and behaviour in the classroom, collaboration, and attributions. Reinforcement was reported to be an important principle of $\mathrm{ABA}$ for teachers to understand and implement, however participants discussed concern in regard to the effective and consistent implementation. Expectations across environments were described by participants as inconsistent. Problem behaviours were defined differently between participants, and between some participants and teachers. Implementing ABA for problem behaviours was reported as accepted by teachers until the behaviour escalated and became, what they felt to be, too disruptive for the classroom. Collaboration between professionals, both outside the classroom and in, was reported to be an important facilitator. As participants stated concern over the implementation of ABA in schools, they often attributed this to teachers' knowledge, training, and collaboration. As this section presented quotes from interviews and follow-up questionnaires to support these five themes, the following section will discuss the themes with a critical lens and in comparison to the literature. 


\section{Chapter 5: Discussion}

The purpose of this study is to investigate factors associated with the implementation of ABA in schools. The focus of this study is based on research that suggests ABA is an effective teaching method for some children with ASD (Dillenburger \& Keenan, 2009). A thematic analysis of interviews and follow-up questionnaires with four behaviour therapists yielded five main themes: 1) reinforcement in the classroom; 2) consistency; 3) ABA and behaviours in the classroom; 4) collaboration, and; 5) attributions. This section examines the meaning of the findings and how they answer the research question guiding this study: what are the facilitators and barriers to the effective implementation of ABA in schools? Before the specific findings and implications are addressed, the theoretical issues of integrating the behavioural theory of ABA with the inclusive perspective of the social model of disability are presented. The findings are then interpreted using a social model of disability and children's rights lens, and are discussed in relation to previous literature on the factors affecting inclusion. Limitations, recommendations for future research, and practical recommendations are then discussed.

\section{Theoretical Issues in Implementing ABA in Schools}

The behavioural perspective of ABA and the inclusive perspective of the social model of disability are similar in that they both focus on restructuring the environment to enhance the learning of children. However there are also many inconsistencies between the two philosophies. ABA stems from a medical model of disability (Nolan \& McBride, 2013), and inclusion is based on a social model of disability. However, ABA can be applied using a social model approach if the focus is education and participation rather than normalization.

Other inconsistencies between the two philosophies exist within themes found in this study. Reinforcement is a central principle of ABA and, when used to teach children with ASD, 
typically focuses on the individual as opposed to a group of individuals. In contrast, inclusion employs a mix of universal design, which focuses on a group of individuals, as well as differentiation. Consistency within the application of ABA principles has been shown to be very important in the effectiveness of ABA (Hayward et al., 2009). Inclusive practices, however, need to have a certain level of flexibility and change, and therefore a certain level of inconsistency. In regard to behaviours in the classroom, both perspectives focus on individual differences. However, ABA has a focus on manipulating the environment to teach and change individual behaviours to increase learning and participation, whereas the inclusive perspective of the social model of disability focuses on removing barriers that impede learning and participation. Models of collaboration also differ between the two, as each have a different understanding of the conceptualization. Although participants in this study did discuss the importance of collaboration between professionals, the behaviour therapist was viewed as the expert as part of their role focuses on teaching teachers how to implement ABA. An inclusive model of collaboration, however, focuses on mutual teaching and compromising between professionals and different approaches.

These inconsistencies between the behavioural perspective of ABA and the inclusive perspective of the social model of disability result in a challenge in integrating the two perspectives into practice. The following discussions of each theme will address this challenge and pose recommendations for an integrated model of ABA and inclusion.

\section{Reinforcement in the Classroom}

The first theme that emerged from the thematic analysis was reinforcement in the classroom. Although all of the behavior therapists identify reinforcement in the classroom as a main facilitator to effective implementation of $\mathrm{ABA}$, they found this not to be present. Instead, 
across interviews and questionnaires, participants noted from their experiences working in classrooms, that there are a number of common barriers to the effective implementation of reinforcement. Generally, participants perceive that not understanding the principles of reinforcement, not seeing the value of reinforcement, not accepting certain types of reinforcement, or incorrectly applying reinforcement may act as barriers to effective application of reinforcement, and therefore, may also act as barriers to the effective implementation of ABA.

Reinforcement is a fundamental concept in ABA, as it underpins many techniques used in ABA (Hayward et al., 2009; Skinner, 1938). The principles of ABA recommended by Koegel et al. (2012) to be applied in inclusive classrooms, such as behavioural protocols, incidental teaching, discrete trial training, PECS, and task analyses, are all based on systems of reinforcement (Hayward et al., 2009). For example, behaviour protocols are based on reinforcing desired behaviours and not reinforcing undesired behaviours (Barnhill, 2005), and incidental teaching requires reinforcement in the natural environment (McGee et al., 1999). Therefore, when reinforcement is not properly implemented, none of the techniques identified in the literature will be properly implemented, and ABA will not be effective. This literature supports participants' perceptions of reinforcement as being an integral principle of ABA.

Participants also commented that they believe reinforcement is not always properly implemented. Alison explained that she believes this is because reinforcing some behaviours is not a typical practice and is unnatural to some teachers. The perception that some principles of ABA are at times unnatural to teachers is supported by research on the attributions teachers hold towards classroom behaviour. Skinner and Hales (1992) found that many teachers attribute children's behaviour to psychoanalytic, developmental, physiological or behavioural characteristics of the child. Most educators in their study attributed behaviour to developmental 
characteristics, which could explain why in the current study behaviour therapists discussed that teachers may have difficulty implementing principles of $\mathrm{ABA}$, such as reinforcement. A developmental assumption associates the cause of behaviour to stages of child development, whereas a behavioural assumption maintains that antecedents and consequences in the environment shape behaviour. Therefore, a teacher with a developmental assumption may react to a behaviour very differently than a teacher with a behavioural assumption. For example, a teacher with a developmental assumption may attend to the child who is tantrumming for attention, while a teacher with a behavioural assumption would see this as reinforcing the behaviour, and instead ignore the behaviour and teach the child another way to obtain the desired attention. Holding a perspective other than a behavioural one may therefore act as a barrier, as it may be more difficult to implement principles of ABA, such as reinforcement, with a lack of understanding or belief of the underlying theory of behaviourism.

Participants suggest that training in ABA would help support teachers to implement principles of $\mathrm{ABA}$, such as reinforcement. What is important to note, however, is that reinforcement already exists in the classroom, and teachers may be implementing reinforcement without realizing it is ABA. To illustrate, putting a sticker on a student's work or saying "good work" are examples of reinforcement (assuming the child values these and finds them reinforcing). A behaviour therapist will often use similar reinforcement, however, to make the reinforcement as specific as possible (Musti-Rao \& Haydon, 2011). For example, instead of saying "good work" to a child, a behaviour therapist may say "good work counting to ten". This type of reinforcement could be easily integrated into a classroom, and would be in line with inclusive practice, as a teacher could apply such specific praise to children with ASD. If a teacher is providing individualized goals for each student, they will be able to match this with 
individualized reinforcement, resulting in easier implementation of ABA. Presenting this argument to teachers may show them that they do have an understanding of reinforcement and are already implementing it. However, some training on schedules of reinforcement in regard to the frequency, duration, immediacy, intensity, saturation, consistency, and type of reinforcement (Skinner, 1989) that is specific to ABA may be beneficial. For example, a teacher may need to learn that they should say "good job counting to ten" immediately every time the child counts to ten, to increase the effectiveness of this reinforcement.

Using a social model of disability lens, barriers to implementing reinforcement can be removed using a truly inclusive approach, such as universal design. Another possibility is to implement reinforcement using a universal design approach which is based on the needs of various children. For example, some children with ASD are very reinforced by sensory stimulation such as touch. Therefore, if one student in the classroom is reinforced by a pat on the arm, the teacher can reinforce many children with a pat on the arm. Another example would be setting up a sticker board, where students can all earn stickers for meeting their goals. This is an example of token reinforcement, and is often used for reinforcing children with ASD (Matson \& Boisjoli, 2009) and could be implemented for the whole classroom.

\section{Consistency}

The behaviour therapists in this study perceive consistency within and across

environments to be a facilitator to the effective implementation of ABA in schools, and perceive inconsistency to be a barrier. Consistency refers to consistency of reinforcement, as well as a general consistency of expectations within and across environments such as schools, ABA centres, and children's homes. 
Three participants discussed the inconsistency around the application of reinforcement systems within the classroom, and view this as a barrier to effective ABA. To illustrate, Alison explained how after some reinforcement systems she implemented began to work, they were not consistently carried out by teachers. This can be interpreted as a need for teachers to understand consistency, because the result of inconsistency can be disruptions in the implementation of ABA overall. This finding is supported by literature, as research shows that consistency is an important factor in $\mathrm{ABA}$, and reinforcement systems in particular, must be systematically faded to be effective (Hayward et al., 2009). Without this consistency, reinforcement is ineffective and the goals of ABA programming are not achieved.

Furthermore, Carolyn explained that to maintain consistency across environments, behaviour protocols have to be altered at times, although compromised protocols may not use the most effective ABA approach. This example illustrates that consistency is a main facilitator, and Carolyn strived to achieve consistency even if it meant slightly compromising an ABA approach. This finding is supported by research that suggests when behaviours are inconsistently reinforced they become more difficult to decrease (Ferster \& Skinner, 1957). Additionally, children with ASD often prefer predictability and clear expectations (Kozima, 2013) which inconsistency between, and within, environments does not provide.

Looking at consistency in the classroom through the lens of inclusion, teachers may be inconsistent at times as an inclusive practice requires flexibility and change. This practice follows the social model of disability, as barriers to learning are constantly assessed and removed so that the environment reflects the needs of the children. However, as there are inconsistencies in inclusive classrooms, certain practices can remain consistent. For example, the set-up of the classroom may change, but can work around the child with ASD who prefers to keep their desk 
in the same location. Similarly, the schedule of the class may change, however the use of a visual schedule to prepare a child with ASD for what comes next may remain consistent. Specifically integrating the consistency of ABA with universal design, a visual schedule could be used for the whole class as opposed to one child with ASD. Visual schedules are frequently used when using ABA to teach children with ASD (Whatley, Gast, Hammond, 2009) and have also been found to benefit children who do not have ASD (Spriggs, Gast, \& Ayres, 2007). Incorporating visual schedules into the classroom is an example of integrating ABA in a manner that benefits the whole classroom. Although inconsistencies may exist in inclusive classrooms, it is how teachers address these inconsistencies and find a balance between the individualization of ABA and universal design. Not only will this increase the effectiveness of ABA and benefit children with ASD, but also children with diverse needs within the classroom.

\section{ABA and Behaviours in the Classroom}

Children with ASD often engage in behaviours such as self-injurious behaviours, aggression, tantrums (Geneva Centre for Autism, n.d.), and behaviours that are deemed "socially unacceptable" such as repetitive or self-stimulatory behaviours (Owren \& Stenhammer, 2013). ABA principles can be applied to decrease these behaviours, and replace them with other behaviours that serve the same, or similar, function (Barnhill, 2005). Participants reported that their role while working in schools is often to focus on behaviours within the classroom. Problem behaviours were defined differently among participants in the study, and some participants stated that there were differences between their definitions and that of teachers. How problem behaviours are defined reflects how a person conceptualizes disability, and this impacts how they view and practice inclusion. From the perceptions of the behaviour therapists in the present study, teachers often hold a low level of tolerance to problem behaviours in the classroom and to 
ABA techniques when these behaviours become disruptive. This level of tolerance is perceived by participants to be a barrier to the implementation of $\mathrm{ABA}$, because when behaviours become disruptive consequences are applied that are not in line with ABA techniques.

When defining problem behaviour, participants provided a variation of responses that reflected different views of disability. For example, Alison focused on behaviours that impede learning or are harmful; Brian focused on behaviours that are harmful; and, Carolyn focused on behaviours that are disruptive and socially inappropriate, such as stimming and scripting. These varying definitions of problem behaviour result in two issues. First, there is not a universal definition of problem behaviours, which can result in inconsistency between applications of ABA. For example, the behaviour therapist in an ABA centre may focus on the child's stimming, while the teacher is focusing on their non-compliance, and the parent is focusing on their aggression. This results in an inconsistency in the application of ABA as well as an inconsistency in expectations of the child, as discussed in the previous section. The second issue with the range in definitions of problem behaviour is that they highlight varying views and understandings of disability. Alison and Brian focus on using ABA to educate, and therefore appear to view disability through a social model lens, which suggests that societal barriers are in place (Barnes, Mercer, \& Shakespeare, 1999). Whereas Carolyn focuses on using ABA for normalization and therefore appears to view disability through a medical model lens, which suggests that the disability resides in the individual (Barnes et al., 1999). As discussed previously in the theoretical framework, the way in which ABA is implemented is shaped by the view of disability. A person such as Carolyn with a medical model approach may focus on a socially unacceptable behaviour such as stimming, in order to normalize the child, whereas a person such 
as Alison or Brian with a social model approach may focus on using ABA to teach math concepts by breaking them down into small, discrete steps.

Research suggests that how a person views disability impacts how they view and understand inclusion (Purdue, 2009). For example, a person who views disability through the lens of the social model sees disability as a result of the environment, and therefore is more likely to manipulate the environment and make modifications to remove the barriers to education and participation. A person who views disability through the lens of the medical model sees disability as residing within the individual, and is less likely to see the value in making modifications in the environment and engaging in inclusive practices. In sum, how teachers view disability can impact their attitudes towards inclusion which in turn, is translated into practice (Jordan, Glenn, \& McGhie-Richmond, 2010).

Along with their own definitions of problem behaviour, participants provided responses to what they believe teachers define as problem behaviours: disruptive behaviours, aggression, non-compliance, and tantrums. Participants were asked how problem behaviours are defined by teachers because they reported that their main focus in the classroom is on problem behaviours and helping the children follow the classroom routine, by learning to listen to the teacher and sit on the carpet. The focus on behavioural issues, especially that of non-compliance, as opposed to academics and social skills suggests that, in the experiences and perceptions of the behaviour therapists in this study, teachers take a medical model approach to understanding ASD. Little discussion was focused on implementing ABA for academics. True inclusion, however, is based on the social model of disability, as it is seen as the educators' responsibility to include and teach all children, and environmental barriers are removed for children to fully participate. Therefore, 
it could be inferred that teachers who hold a medical model view of disability, do not engage in inclusive practices in the classroom, and may not implement principles of ABA.

Participants are asked to apply ABA techniques to decrease problem behaviours within the classroom. From the perceptions of the behaviour therapists in the present study, teachers have low levels of tolerance to problem behaviours in the classroom, and to ABA techniques, when these behaviours become disruptive. However, as participants had varying definitions of problem behaviours and perspectives on disability, their definitions of tolerance are subjective and likely variable as well. Implementing ABA techniques to reduce a behaviour often results in the behaviour increasing before it decreases (Barnhill, 2005), and participants perceive this to be unnatural to some people, and can also be disruptive in a classroom. The level of tolerance to behaviours, and teachers' difficulty with behaviours once they reach a certain level speaks to one of the challenges of inclusion. As Carolyn said, when behaviours escalate teachers sometimes say, "we can't let this happen". As a behaviour escalates it may be attended to in order to stop it right away, and this level of tolerance can act as a barrier to the full implementation of $\mathrm{ABA}$, and in turn to the support children with ASD.

Besides the consequences of behaviour, antecedent strategies are integral in the application of ABA to increase or decrease behaviours (Barnhill, 2005). This is also consistent with an inclusive approach as the focus is on modifying the environment to reflect the needs of the class. Therefore, to integrate $\mathrm{ABA}$ with an inclusive perspective, antecedent modifications can be made at a classroom level. For example, many children with ASD are very sensitive to loud noises, which can trigger behaviours (Geneva Centre for Autism, n.d.). Reducing the noise throughout the classroom is an example of a classroom level accommodation. Or for children with ASD who have difficulty sitting still for periods of time, the entire classroom can take 
movement breaks. Or part of the classroom can be designated for children who prefer to move while learning, while part is for children who prefer to sit still. The focus here is on changing the culture of the classroom and accepting a range of behaviours. When the teacher constructs the classroom to integrate principles of ABA with universal design these "problem" behaviours are not a barrier to inclusion.

\section{Collaboration}

According to the perceptions of behaviour therapists in the study, collaboration between teachers, behaviour therapists, EAs, ASD consultants, and parents is an important facilitator in implementing ABA in schools. Participants discussed how each person can take on a different responsibility, either inside or outside of the classroom, and work as a team to effectively implement $\mathrm{ABA}$ and support children with ASD. However, participants perceive some policies as restricting to their roles and as barriers to them being part of the team and collaborating with others.

The current study only included the perceptions of behaviour therapists; however the importance of collaboration in regard to inclusion is supported by the literature. For example, Kosmerl (2011) found similar results in regard to teachers' perceptions of collaboration, as teachers reported that in order to include children with ASD in their classroom they would need the support of other professionals, and specifically stated access to collaboration with an ASD consultant. The importance of collaboration was also stated by teaching assistants (Downing et al., 2000) and occupational therapists (Bose \& Hinojosa, 2008) working in inclusive classrooms.

Participants were asked about their perceptions of ideal roles of professionals. Alison outlined what she believes should be the role of the teacher, behaviour therapist, teacher, EA, and parent, and how each person should work together outside of the classroom. She explained 
that teachers should lead the class and EAs should help support by ensuring follow-through. ASD consultants should set up and continuously adjust the classroom to be conducive to the work of the behaviour therapists, who should focus on the child-specific application of ABA. She also stated that besides the understanding of ABA, the individualization of programming is important, which speaks to the notion of inclusion, as inclusion is based on "responding to diversity" with "changes and modifications in content, approaches, structures and strategies" (UNESCO, 2005, pg. 13). She explained that, in her opinion, parents and behaviour therapists should create the individualization piece as they know the children best. She explained that behaviour therapists often work with children for a number of years before they enter the school system. In cases such as these, behaviour therapists know the child very well and are able to apply child-specific ABA techniques to the programming. This emphasizes the potential of collaboration. People who know the child well collaborating with teachers who know education, and ASD consultants who know how to train teachers and how ABA is implemented in schools. Although Alison's suggestion of behaviour therapists providing the child-specific application of $\mathrm{ABA}$ and the individualization piece is warranted by their previous relationships with the child, it is important to note that true collaboration comes from more than one direction. It is contradictory to assume that the parent and behaviour therapist are experts on the child, and that it is the teachers' responsibility to teach the child. Therefore, it can be recommended that behaviour therapists work with the teacher to support the complex needs of students with ASD; however multiple teaching perspectives must be combined for true collaboration, and therefore true inclusion, to exist. Teachers' role must be valued, and entering another professional's workspace as an expert can be met with resistance (Hargreaves, 2004). Therefore, the role of the 
behaviour therapist could include discussion, consultation, and collaboration with the teachers, as well as working with children to support their needs, within the teachers' lesson plans.

Participants also perceive collaboration within the classroom as a facilitator in implementing ABA. Participants recommended opportunities for one-to-one support for the child, or an increased staff to student ratio, as there are times when extra support is needed to implement ABA. For example, Diane discussed how at times it is nearly impossible for a teacher to reinforce each targeted behaviour when they have a whole class to work with. The notion of collaboration and the roles and responsibilities of individuals are especially important in this case, as research has suggested that when a student has one-to-one support, this may shift the responsibility of teaching the child from the teacher to the other professional, such as the EA or behaviour therapist, which impacts inclusion and learning (Jordan et al., 2010). If the teacher does not view a child as their responsibility and a part of their classroom, the teacher is not practicing inclusive education. Behaviour therapists identified collaboration as a facilitator to $\mathrm{ABA}$ in the classroom; however this suggestion must be taken with caution. If the education of children with ASD is not seen as the responsibility of the teacher, this can act as a barrier to the educational and social inclusion of the child.

Integrating a behavioural perspective with a social model of inclusion can result in a true model of collaboration. Participants discussed that in order for ABA to be effective, teachers must understand principles such as reinforcement and consistency. However, behaviour therapists must also understand the group context and adapting for a group. Relating back to a previous example of using a sticker board for the reinforcement of all children in the classroom, teachers must understand how this reinforcement must be applied consistently, contingently, and immediately in order to maximize its effectiveness (Skinner, 1989), and behaviour therapists 
must understand how to integrate a token board for the whole classroom. Knowledge of ABA can be integrated with knowledge of inclusive teaching practices, which has the potential of benefitting many children in the class.

As collaboration was reported to be a facilitator, current policy was reported to be a barrier to what participants described as ideal roles and therefore to successful collaboration. Carolyn reported that, at times, policy restricts behaviour therapists from entering the school, as schools in Toronto are not required to allow third parties into the classroom (Toronto District School Board, 2012). This barrier was also reported in other research, as Purdue (2009) found that some policies are beneficial to inclusion, however others do not allow room for flexibility, which is needed to be inclusive.

\section{Attributions}

Participants reported that they believe teachers are often either incorrectly implementing or not implementing ABA strategies when working with children with ASD, and attributed this to a lack of knowledge of ABA and support in the classroom. Participants discussed how, in their opinions, teachers' lack of knowledge acts as a barrier to effective implementation. They then attributed this lack of knowledge to a lack of education and training in ABA. This is the perception of the behaviour therapists in the study. As teachers were not included in the study it does not necessarily represent teachers' actual knowledge. However, this perceived lack of knowledge is critical because research has shown that a teacher's knowledge impacts their teaching (Cologon, 2012), and other studies have shown that some teachers feel they do not have the knowledge or training to meet the academic, behavioural, and social needs of children with ASD (Horrocks et al., 2008). Research has even shown that support staff who are hired to work directly with children with disabilities are not properly trained (Downing et al., 2000). 
Linking these findings to attribution theory (Kelley, 1973), participants attributed what they perceived as lack of implementation of ABA to lack of teacher knowledge, which is internal and is supported by the attribution error (Pettigrew, 1979). This error theorizes that people naturally attribute negative behaviours of others to internal dispositions, rather than circumstances, but attribute their own negative behaviours to situational causes. However, participants attributed this perceived lack of teachers' knowledge to teachers not receiving the proper education or training in $\mathrm{ABA}$, which has an external or situational cause.

\section{What Would an Inclusive Classroom With ABA Include?}

Participants discussed the importance of reinforcement in the classroom and an inclusive classroom with ABA would include the implementation of this principle at a classroom level. The need for consistency was reported by participants; however they did not address the need for flexibility in inclusive classrooms. An inclusive classroom with ABA would include consistent implementation of the principles of $\mathrm{ABA}$, and use methods such as visual schedules for the whole class to address these inconsistencies.

Consequences that are not aligned with the principles of $\mathrm{ABA}$ for problem behaviours were reported as barriers to $\mathrm{ABA}$. As this would be taken into account in an inclusive classroom, there would be a focus on antecedent strategies and tolerance at a classroom level. Participants discussed the need for collaboration; however the focus tended to be on teaching teachers about ABA, as opposed to compromising and integrating different philosophies. A model of collaboration in an inclusive classroom with $\mathrm{ABA}$ would integrate the behavioural perspective with the inclusive perspective to incorporate $\mathrm{ABA}$ into universal design.

\section{Summary}


According to the perceptions of behaviour therapists in this study, the following are viewed as facilitators to implementation of $\mathrm{ABA}$ in schools: implementing reinforcement in the classroom, consistency within and across environments, a level of tolerance for disruptive behaviours in the classroom, and collaboration between professionals and parents. Specifically, participants attribute proper implementation of the principles of ABA to knowledge and understanding of the techniques in ABA. It could also be inferred that holding a social model view of disability positively impacts one's attitudes towards inclusion, and acts as a facilitator towards the implementation of $\mathrm{ABA}$ in the classroom.

Barriers to implementation of $\mathrm{ABA}$ in schools were reported to be: not understanding the principles of reinforcement, not seeing the value of reinforcement, not accepting certain types of reinforcement, or incorrectly applying reinforcement, inconsistency within and across environments, a low level of tolerance to disruptive behaviours, and policy which restricts collaboration between professionals. It could also be inferred that holding a medical model view of disability negatively impacts one's attitudes towards inclusion, and acts as a barrier towards the implementation of ABA in the classroom.

It is the perspective of participants that teachers do not value or understand reinforcement; however a lack of implementation could also be caused by their theoretical perspective on behaviours, such as a developmental approach instead of behavioural approach, or by their theoretical perspective on disability and inclusion. If they hold a medical model of disability perspective, they see the disability within the child, and do not see the value of implementing reinforcement to remove the barriers to education for children with ASD. Problem behaviours are also defined differently between participants, specifically between participants with opposing views of disability. It is also the perspective of participants that collaboration 
between professionals includes the roles of behaviour therapists. However, collaboration must be seen through an inclusive lens to facilitate ABA as discussed in this study. True collaboration does not include an "expert", as this may devalue the expertise of others as well as shift the responsibility of teaching the child away from the teacher, which is the goal of implementing ABA in the classroom.

\section{Limitations}

It should be noted that the themes found in the present study were formed through the perceptions of behaviour therapists. Teachers were not interviewed and therefore it cannot be assumed that results reflect their perceptions as well. However, other research on the perceptions of teachers supports the perceptions of behaviour therapists. For example, teachers stated that they should not be expected to teach children with ASD without proper training and support, and that in order to create an inclusive classroom they would need supports such as a general care assistant, training, and access to an ASD consultant (Kosmerl, 2011).

The support of other research strengthens the validity of the findings; however, as this was a qualitative study with a small sample size of four participants, results are not necessarily generalizable to other people and settings (Morrow, 2005). However, results of qualitative research can be transferred to other situations, depending on the similarity between settings (Lincoln \& Guba, 1985). The facilitators and barriers to effective implementation of ABA described by these participants can possibly be applicable to others in similar situations, such as other classrooms across Ontario.

Interviews were conducted in public places, and this could have potentially impacted participants' responses. The two interviews conducted in libraries took place in private study rooms; however the other two interviews took place in local coffee shops. Although these 
locations were chosen by participants, it is possible that they were less comfortable disclosing certain information or elaborating on certain points due to confidentiality. The data collected from the interviews lacked elaboration, which prompted the follow-up questionnaires, and the location of the interviews may be an explanation for this limitation in the data.

\section{Future Research}

The present study investigated ABA with the social model as a core principle. As discussed in the literature review, outcome measures in $\mathrm{ABA}$ research are typically defined in normative terms, such as decreasing socially unacceptable behaviours like stimming (Nolan \& McBride, 2013). Further research based on the application of ABA in line with the social model is warranted. Particularly, research on the outcome measures for the implementation of ABA in schools that are in line with the social model is needed.

This is an exploratory study with the purpose of gaining information about policy implementation of PPM 140. Future research could investigate these themes on a larger scale, perhaps using quantitative research, to increase the generalizability of results. A similar study investigating teachers' perceptions of the facilitators and barriers to implementation of $\mathrm{ABA}$ in schools would provide another perspective of the issue, and it would be interesting to compare those results with the perceptions and attributions of behaviour therapists in the present study. Additionally, participants could include ASD consultants, EAs, parents, and the child to obtain many different perspectives on factors that impact the implementation of ABA in schools.

\section{Conclusions and Recommendations}

The effective implementation of ABA in schools is impacted by a variety of facilitators and barriers. A thematic analysis of data from interviews and questionnaires with behaviour therapists provided five themes based on their perceptions: reinforcement in the classroom, 
consistency, ABA and behaviours in the classroom, collaboration, and attributions. Throughout these themes, participants specifically reported what they believe to affect the implementation of ABA in classrooms.

The behaviour therapists that participated in this study are hired by the children's parents, as opposed to the school board, to implement ABA therapy to children with ASD. Parents of children with ASD pay for the behaviour therapists through either government funding or out of pocket (Gordon, 2012b). PPM 140 is in place to extend ABA therapy and provide free and accessible education for students with ASD in Ontario (Ontario Ministry of Education, 2007). However, this policy does not include the collaboration of behaviour therapists in the classroom. Therefore, it is recommended that in order for the model of collaboration discussed by participants to exist, school boards should consider the role of behaviour therapists in the classroom. Currently, ASD consultants are hired by the school board to provide general ABA consultation and training, but what is missing is the child-specific support, consultation, and collaboration that could be provided by behaviour therapists.

Besides collaboration between professionals, theoretical collaboration between ABA and inclusive practices is also recommended in order to provide an application of ABA that fits into a classroom context. Participants specifically discussed their perceptions of the need for teacher education and training in ABA. Therefore, it is recommended that teachers are educated in ABA. This could be achieved through teachers college, as Diane suggested, or through professional development and general ABA training and consultation provided by ASD consultants, as Alison suggested. Furthermore, this study discusses an application of ABA in inclusive classrooms that is based on the social model of disability, and besides participants' recommendations of knowledge of ABA, this implementation requires other critical levels of knowledge. Therefore, a 
theoretical understanding of the social model of disability and inclusive education, as well as ABA, is recommended in pre-service and in-service teacher preparation courses as this would best support an application of ABA that fits into a classroom context. 


\section{Introductory Script}

\section{Appendix A: Interview Protocol}

$\mathrm{Hi}$, my name is Heather. Thank you for coming. I am a graduate student in the Early Childhood Studies program at Ryerson University, and I am conducting a study on the implementation of Applied Behaviour Analysis (ABA) in schools. I would like to speak with you today because you are an important part of the support system for children with autism. For this study I will be talking to both elementary school teachers and autism consultants, and trying to uncover facilitators and barriers to implementation of ABA in schools. I have a list of questions to ask you about your perceptions and experiences of ABA in the classroom.

Before we begin, please take a few minutes to read over and sign this consent form. It is the same as the one I sent you. If it is okay with you, I will audio-record the interview. This way I can be sure I get all the details for the study. Only I will have access to the interview and everything you say will be completely confidential. Do you have any questions before we begin?

\section{Closing Script}

Thank you very much for your time and participation today. I expect to complete the study by September and could send you a copy of the findings if you like. If you have any questions about the interview or study please do not hesitate to email me.

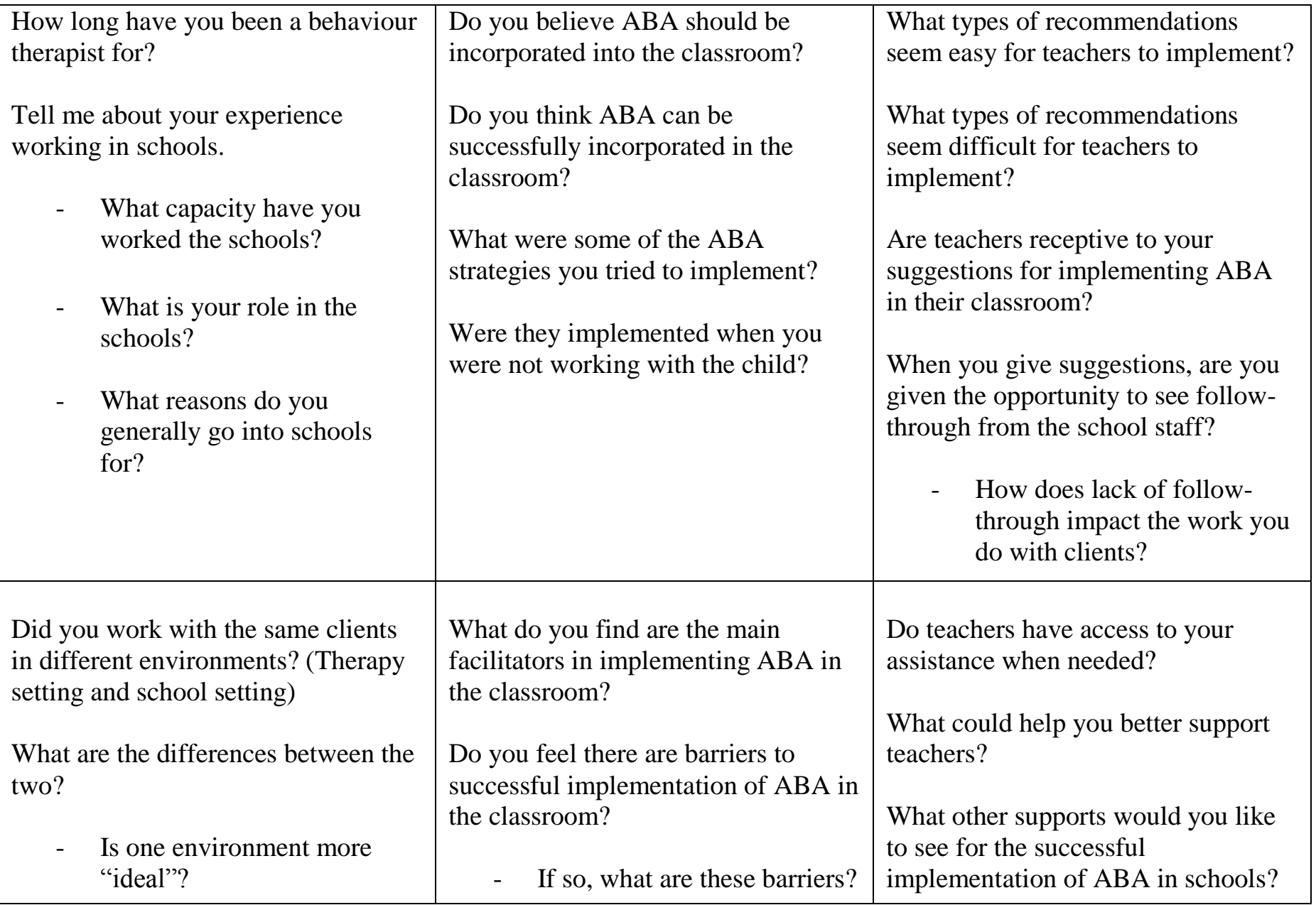




\section{Appendix B: Follow-up Questionnaire}

Thank you again for sharing your experiences of ABA in the classroom. As a follow-up to speaking with you and other participants, I have a few more questions I would like to ask. When answering, please be as specific as possible and provide examples.

In the interviews, participants discussed problem behaviours that are targeted for ABA intervention in the schools.

1. What do teachers define as problem behaviours? Can you provide a list of examples?

2. What do you define as problem behaviours? Can you provide a list of examples?

3. What is the effect of these behaviours targeted in school and who is affected by them, for example, is it a problem to other children, the teacher, parents, the child, the therapist, etc.?

In the interviews, several participants discussed ABA knowledge and principles.

4. Which principles do you think need to be articulated more clearly for teachers? Please be specific.

In the interviews, several participants discussed training needs for teachers:

5. In what areas do you think teachers need training?

6. ASD consultants provide workshops and training in ABA to teachers. What do you think is most important for ASD consultants to address with teachers? Specifically, are there certain skills or techniques that teachers could learn to implement in the classroom?

In the interviews, several participants stated that ABA can be implemented in classrooms.

7. Assuming the training, resources, support, funding, etc. were all in place, what would the roles of the teacher, consultant, and others be in a classroom with successful integration of ABA strategies?

Two final follow up questions:

8. How can ABA help to achieve the goals of the classroom?

9. How could you see your role expand to contribute more in the classroom? For example, are there any current classroom activities or interactions that you might have observed that you think would work well with, or complement, or be consistent with, the principles of ABA? 
Appendix C: Recruitment Email

Are you a Behaviour Therapist?

Have you worked in a public school, supporting a child with autism in their classroom?

\title{
We want to hear from you!!
}

Talk to us about your experiences with Applied Behaviour Analysis

\author{
$(\mathrm{ABA})$ in the classroom
}

What is the study about?

- A research project looking at behaviour therapists' perceptions and experiences of supporting children with autism in the classroom.

- The purpose of this study is to investigate the facilitators and barriers to implementation of ABA in schools.

What do we want from you? 
- Participate in a one-on-one, open-ended interview about your experiences and perceptions of ABA in the classroom.

- Participation will take about an hour of your time at a location convenient to you.

Your decision to take part in the study will not affect your relationship with the Ryerson University or your place of employment.

For more information, please contact:

Heather Cowan, MA (cand.)

Early Childhood Studies, Ryerson University

heather.cowan@ryerson.ca

This is a graduate student-led research project with faculty supervision. 


\section{Appendix D: Consent Form}

\section{Ryerson University \\ Consent Agreement}

\section{Effective Implementation of ABA in Schools}

You are being asked to participate in a research study. Before you give your consent to be a volunteer, it is important that you read the following information and ask as many questions as necessary to be sure you understand what you will be asked to do.

\section{Investigators:}

This is a graduate student-led research project with faculty supervision.

Graduate Student: Heather Cowan, M.A. (cand.) Early Childhood Studies, Ryerson University Faculty Supervisor: Dr. Kathryn Underwood, Ph.D., Early Childhood Studies, Ryerson University

\section{Purpose of the Study:}

The current Ontario policy (PPM 140) is the implementation of Applied Behaviour Analysis (ABA) and other evidence-based strategies to support children with autism in public school classrooms. With increasing numbers of children being diagnosed with autism it is important to assess the facilitators and barriers in implementing this policy, and work towards effective academic and social inclusion. Through interviews with behaviour therapists, this study will potentially provide insight to the facilitators and the barriers to effective implementation of ABA in schools.

\section{Description of the Study:}

Through an individual interview, you will provide your perceptions and experiences of the facilitators and barriers to implementation of ABA in the classroom. This interview will take about an hour of your time in a location convenient for you. A private room at a local library can be booked to ensure confidentiality.

The following are examples of questions that will be asked in the interviews: What capacity have you worked the schools? What is your role in the schools? Do you think ABA can be successfully incorporated in the classroom? Do you feel there are barriers to successful implementation of $\mathrm{ABA}$ in your classroom? If so, what are these barriers?

\section{Risks or Discomforts:}

It is possible that you may feel uncomfortable answering some of the questions or elaborating on any of the concepts established during an interview. Although no identifying information will be used in the study, if there are a limited number of employees in your position then identification may be possible. You are free to refuse to answer any questions and/or stop the interview for any reason. Additionally, you have the right to withdraw from the study altogether, and the audio-recordings that have been made before your withdrawal will be 
destroyed, and thus will not be used for the purpose of this study. Please note your audio recordings and data can be removed up to July 15, 2013, after which withdrawal participation is not possible as the study will be complete.

\section{Benefits of the Study:}

This is an exploratory study with the purpose of gaining information about policy implementation. It cannot be guaranteed that you will receive any personal benefits from participating in this study. However, it is hoped that your participation will provide insight to the facilitators and the barriers to effective implementation of ABA in schools.

\section{Dissemination:}

The findings of the study will be used for a graduate level Major Research Paper. It will be presented to Ryerson University in partial fulfillment of the requirements for the degree of Master of Arts in the program of Early Childhood Studies. Participants will be provided with a summary of the findings.

\section{Confidentiality:}

No identifying information (names, schools, etc.) will be recorded, and pseudonyms will be used to ensure confidentiality. Quotations from the interview may be used in the report; however no names or identifying information will be used.

With your consent, interviews will be audio-recorded and transcribed, with no identifying information attached. Only the researcher will have access to the recorded interviews. They will be stored on password protected data keys for transportation, and then on password protected computers. They will be stored for two years after completion of the study before being destroyed.

\section{Incentives to Participate:}

You will not be paid to participate in this study.

\section{Voluntary Nature of Participation:}

Participation in this study is voluntary. Your choice of whether or not to participate will not influence your future relations with Ryerson University, or your place of employment. If you decide to participate, you are free to withdraw your consent and to stop your participation at any time without penalty. At any particular point in the study, you may refuse to answer any particular question or stop participation altogether.

\section{Questions about the Study:}

If you have any questions about the research now, please ask. If you have questions later about the research, you may contact.
Researcher:
Heather Cowan
heather.cowan@ryerson.ca
Faculty Supervisor: $\quad$ Dr. Kathryn Underwood, (416) 979-5000 ext. 2519
kunderwood@ryerson.ca 
If you have questions regarding your rights as a human subject and participant in this study, you may contact the Ryerson University Research Ethics Board (REB) for information.

$\begin{array}{ll}\text { REB Coordinator: } & \text { Toni Fletcher } \\ & \text { toni.fletcher@ryerson.ca } \\ & \text { Research Ethics Board } \\ & \text { Ryerson University } \\ & 350 \text { Victoria Street } \\ & \text { Toronto, ON M5B 2K3 } \\ & 416-979-5042\end{array}$

\section{Agreement:}

Your signature below indicates that you have read the information in this agreement and have had a chance to ask any questions you have about the study. Your signature also indicates that you agree to be in the study and have been told that you can change your mind and withdraw your consent to participate at any time. You have been given a copy of this agreement.

You have been told that by signing this consent agreement you are not giving up any of your legal rights.

Name of Participant (please print)

Signature of Participant

Date

Signature of Investigator

Date

\section{Audiotape Recording Agreement:}

Your signature below indicates that you are aware that this interview will be audiorecorded and verbatim transcriptions will be later made from the audio-recording. No identifying information will be attached to the recording.

Signature of Participant

Date

Signature of Investigator

Date 
Once the study is complete, I am happy to provide you with a summary of the findings, should you be interested. If so, please sign below.

Signature of Participant

Date

Preferred Contact Information 


\section{References}

Adcock, J., \& Cuvo, A. J. (2008). Enhancing learning for children with autism spectrum disorders in regular education by instructional modifications. Research in Autism Spectrum Disorders, 3, 319-328.

American Psychological Association. (2013). Diagnostic and statistical manual of mental disorders (5th ed.). Washington, DC: Author.

Autism Society Canada. (2013). What are autism spectrum disorders? Retrieved from http://www.autismsocietycanada.ca/index.php?option=com_content\&view=article\&id=1 $7 \&$ Itemid $=51 \&$ lang $=$ en

Autism Speaks Canada. (2013). Facts and stats. Retrieved from http://www.autismspeaks.ca/about-autism/facts-and-stats

Baer, D. M., Wolf, M. M., \& Risley, T. R. (1968). Some current dimensions of applied behavior analysis. Journal of Applied Behavior Analysis, 1, 91-97.

Barnes, C., Mercer, G., \& Shakespeare, T. (1999). Exploring disability: A sociological introduction. Cambridge, UK: Polity Press.

Barnhill, G. P. (2005). Functional behavioural assessment in schools. Intervention in School and Clinic, 40(3), 131-143.

Bennett, S., Dworet, D., \& Weber, K. (2008). Special education in Ontario schools (6th ed.). St. Davids, ON: Highland Press.

Berg, W. K., Wacker, D. P., Cigrand, K., Merkle, S., Wade, J., Henry, K. \& Wang, Y. (2007). Comparing functional analysis and paired-choice assessment results in classroom settings. Journal of Applied Behavior Analysis, 40, 545-552. 
Bose, P., \& Hinojosa, J. (2008). Reported experiences from occupational therapists interacting with teachers in inclusive early childhood classrooms. AJOT: American Journal of Occupational Therapy, 62, 289-297.

Braun, V., \& Clarke, V. (2006). Using thematic analysis in psychology. Qualitative Research in Psychology, 3(2), 77-101.

Buysse, V., Skinner, D., \& Grant, S. (2001). Toward a definition of quality inclusion: Perspectives of parents and practitioners. Journal of Early Intervention, 24(2), 146-161.

Cascio, M. A. (2012). Neurodiversity: Autism pride among mothers of children with autism spectrum disorders. Intellectual and Developmental Disabilities, 50(3), 273-283.

Charlop-Christy, M. H., Carpenter, M., Le, L., LeBlanc, L. A., \& Kellet, K. (2002). Using the picture exchange communication system (PECS) with children with autism: Assessment of PECS acquisition, speech, social-communicative behaviour, and problem behaviour. Journal of Applied Behaviour Analysis, 35(3), 213-231.

Charmaz, K. (2008). Grounded theory as an emergent method. In Hesse-Biber, S. N., \& Leavy, P. (Eds.), Handbook of Emergent Methods (pp. 155-170). New York, NY: The Guilford Press.

Cologon, K. (2012). Confidence in their own ability: Postgraduate early childhood students examining their attitudes towards inclusive education. International Journal of Inclusive Education, 16, 1155-1173.

Committee on the Rights of the Child (2006). General Comment No. 9: The rights of children with disabilities. United Nations.

Corbin, J., \& Strauss, A. (1990). Grounded theory research: Procedures, canons, and evaluative criteria. Qualitative Sociology, 13, 3-21. 
Creswell, J. W. (2009). Research design: Qualitative, quantitative, and mixed methods approaches. Thousand Oaks: Sage Publications Inc.

DiCicco-Bloom, B., \& Crabtree, B. F. (2006). The qualitative research interview. Medical Education, 40, 314-321.

Dillenburger, K., \& Keenan, M. (2009). None of the As in ABA stand for autism: Dispelling the myths. Journal of Intellectual and Developmental Disability, 34(2), 193-195.

Downing, J. E., Ryndak, D. L., \& Clark, D. (2000). Paraeducators in inclusive classrooms: Their own perceptions. Remedial and Special Education, 21, 171-181.

Dunlap, G., Kern, L., \& Worcester, J. (2001). ABA and academic instruction. Focus on Autism and Other Developmental Disabilities, 16(2), 129-136.

Eldevik, S., Hastings, R. P., Hughes, J. C., Jahr, E., Eikeseth, S., \& Cross, S. (2009). Metaanalysis of early intensive behavioral intervention for children with autism. Journal of Clinical Child \& Adolescent Psychology, 38, 439-450.

Esmail, S., Darry, K., Walter, A., \& Knupp, H. (2010). Attitudes and perceptions towards disability and sexuality. Disability and Rehabilitation, 32(14), 1148-1155.

Evans, C., \& Waring, M. (2011). How can an understanding of cognitive style enable trainee teachers to have a better understanding of differentiation in the classroom? Educational Research for Policy and Practice, 10(3), 149-169.

Fernell, E., Hedvall, A., Norrelgen, F., Eriksson, M., Hoglund-Carlsson, L., Barnevik-Olsson, M., Syensson, L., Holm, A., Westerlund, J., \& Gillberg, C. (2011). Developmental profiles in preschool children with autism spectrum disorders referred for intervention. Research in Developmental Disabilities, 31(3), 790-799. 
Ferster, C. B., \& Skinner, B. F. (1957). Schedules of reinforcement. Upper Saddle River, NJ: Prentice Hall.

Fisher, D., Roach, V., \& Frey, N. (2002). Examining the general programmatic benefits of inclusive schools. International Journal of Inclusive Education, 6, 63-78.

Frieder, J. E., Peterson, S. M., Woodward, J., Crane, J., \& Garner, M. (2009). Teleconsultation in school settings: Linking classroom teachers and behavior analysts through web-based technology. Behavior Analysis in Practice, 2(2), 32-39.

Geneva Centre for Autism. (2007). Autism spectrum disorders: A brief overview. Retrieved from http://www.autism.net/resources/about-autism/42-autism-spectrum-disorders-a-briefoverview.html

Geneva Centre for Autism. (n.d.) Other symptoms of ASD. Retrieved from http://autism.net/resources/about-autism/216-other-symptoms-of-asd.html

Gibson, W. J., \& Brown, A. (2009). Working with qualitative data. London: SAGE Publications. Goodman, L. A. (1961). Snowball sampling. The Annals of Mathematical Statistics 32, 148-170. Gordon, A. (2012a, November 23). The Autism Project: Children face up to four-year wait for therapy. The Toronto Star. Retrieved from http://www.thestar.com/news/gta/2012/11/23/the_autism_project_children_face_up_to_f ouryear_wait_for_therapy.html

Gordon, A. (2012b, November 10). The Autism Project: The odyssey to get your child diagnosed and treated. The Toronto Star. Retrieved from http://www.thestar.com/news/investigations/2012/11/10/the_autism_project_the_odyssey _to_get_your_child_diagnosed_and_treated.html 
Grey, I. M., Honan, R., McClean, B., \& Daly, M. (2005). Evaluating the effectiveness of teacher training in Applied Behavior Analysis. Journal of Intellectual Disabilities, 9(3), 209-227.

Hargreaves, A. (2004). Inclusive and exclusive educational change: emotional responses of teachers and implications for leadership. School Leadership \& Management, 24, 287-309.

Hauser-Cram, P., Bronson, M. B., \& Upshur, C. C. (1993). The effects of the classroom environment on the social and mastery behavior of preschool children with disabilities. Early Childhood Research Quarterly, 8, 479-497.

Hayward, D. W., Gale, C. M., \& Eikeseth, S. (2009). Intensive behavioural intervention for young children with autism: A research-based service model. Research in Autism Spectrum Disorders, 3, 571-580.

Healy, O., Kenny, N., Leader, G., \& O’Connor, J. (2008). Three years of intensive applied behavior analysis: A case study. The Journal of Early and Intensive Behavioral Intervention, 5, 4-22.

Horrocks, J. L., White, G., \& Roberts, L. (2008). Principals' attitudes regarding inclusion of children with autism in Pennsylvania public schools. Journal of Autism Developmental Disorders, 38, 1461-1473.

Huskens, B., Reijers, H., \& Didden, R. (2012). Staff training effective in increasing learning opportunities for school-aged children with autism spectrum disorders. Developmental Neurorehabilitation, 15(6), 435-447.

Jaarsma, P., \& Welin, S. (2011). Autism as a natural human variation: Reflections on the claims of the neurodiversity movement. Health Care Analysis, 20, 20-30.

Jimenez, T. C., Graf, V. L., \& Rose, E. (2007). Gaining access to general education: The promise of universal design for learning. Issues in Teacher Education, 16(2), 41-54. 
Jordan, A., Glenn, C., \& McGhie-Richmond, D. (2010). The Supporting Effect Teaching (SET) project: The relationship of inclusive teaching practices to teachers' beliefs about disability and ability, and about their roles as teachers. Teaching and Teacher Education, 26, 259-266.

Kalambouka, A., Farrell, P., Dyson, A., \& Kaplan, I. (2007). The impact of placing pupils with special educational needs in mainstream schools on the achievement of their peers. Educational Research, 49(4), 365-382.

Kazi, A. M., \& Khalid, W. (2012). Questionnaire designing and validation. The Journal of the Pakistan Medical Association, 62(5), 514-516.

Kelley, H. H. (1973). The processes of causal attribution. American Psychologist, 28(2), 107128.

Kelley, H. H., \& Michela, J. L. (1980). Attribution theory and research. Annual Review of Psychology, 31, 457-501.

Kochhar, C. A., \& West, L. L. (1996). Handbookfor successful inclusion. Frederick, MD: Aspen Publishers, Inc.

Koegel, L., Matos-Freden, R., Lang, R., \& Koegel, R. (2012). Interventions for children with autism spectrum disorders in inclusive school settings. Cognitive and Behavioral Practice, 19, 401-412.

Kosmerl, K. M. (2011). A comparative investigation of general and special education elementary teachers' beliefs about including students with an educational disability of autism in the general education setting. Widener University. ProQuest Dissertations and Theses, 142. 
Kozima, H. (2013). Cognitive granularity: A new perspective over autistic and non-autistic styles of development. Japanese Psychological Research, 55(2), 168-174.

Lincoln, Y. S., \& Guba, E. G. (1985). Naturalistic inquiry. Newbury Park, CA: Sage.

Lowdermilk, J., Martinez, D., Pecina, J., \& Beccera, L. (2012). Behavior Breakthroughs ${ }^{\mathrm{TM}}$ : Designed to teach ABA techniques. TechTrends, 56(3), 29-35.

Lovaas, O. I. (1987). Behavioral treatment and normal educational and intellectual functioning in young autistic children. Journal of Consulting and Clinical Psychology, 55, 3-9.

Magiati, I., Charman, T., \& Howlin, P. (2007). A two-year prospective follow-up study of community-based early intensive behavioural intervention and specialist nursery provision for children with autism spectrum disorders. Journal of Child Psychology and Psychiatry, 48, 803-812.

Makrygianni, M., \& Reed, P. (2010). A meta-analytic review of the effectiveness of behavioural early intervention programs for children with autistic spectrum disorders. Research in Autism Spectrum Disorders, 4, 577-593.

Marvasti, A. B. (2004). Qualitative research in sociology. London, England: SAGE.

Matson, J. L., \& Boisjoli, J. A., (2009). The token economy for children with intellectual disability and/or autism: A review. Research in Developmental Disabilities, 30(2), 240248.

McGee, G., Morrier, M. J., \& Daly, T. (1999). An incidental teaching approach to early intervention for toddlers with autism. Journal of the Association for Persons with Severe Handicaps, 24(3), 133 - 146.

Mehra, B. (2002). Bias in qualitative research: Voices from an online classroom. The Qualitative Report, 7(1). Retrieved from http://www.nova.edu/ssss/QR/QR7-1/mehra.html 
Morrow, S. L. (2005). Quality and trustworthiness in qualitative research in counseling psychology. Journal of Counseling Psychology, 52, 250-260.

Mueller, M. M., Palkovic, C. M., \& Maynard, C. S. (2007). Errorless learning: Review and practical application for teaching children with pervasive developmental disorders. Psychology in the Schools, 44(7), 691-700.

Musti-Rao, S., \& Haydon, T. (2011). Strategies to increase behavior-specific teacher praise in an inclusive environment. Intervention in School and Clinic, 47(2), 91-97.

National Epidemiologic Database for the Study of Autism in Canada. (2012). Changes in the prevalence of Autism Spectrum Disorders in Newfoundland and Labrador, Prince Edward Island, and Southeastern Ontario. Retrieved from http://authoring.wp.queensu.ca/lenya/nedwww/live/Publications/FamilyUpdates/NEDSA C_Report_March2012.pdf

Neisser, U. (1997). Rising scores on intelligence tests. American Scientist, 85(5), 440-447.

Nolan, J., \& McBride, M. (2013). Embodied Semiosis: Autistic 'stimming' as sensory praxis. Paper presented at the American Educational Research Association, San Francisco, April 2013.

Ontario Government. (2005). Identification and Placement of Exceptional Pupils, Ontario Regulation 181/98. Retrieved from http://www.elaws.gov.on.ca/html/regs/english/elaws_regs_980181_e.htm

Ontario Ministry of Children and Youth Services. (2011). Programs and services for children with autism. Retrieved from http://www.children.gov.on.ca/htdocs/English/topics/specialneeds/autism/programs.aspx 
Ontario Ministry of Children's Services and Ontario Ministry of Community and Social Services. (2003). Intensive Early Intervention Program (IEIP) Source Document. Presented by the Ontario Government in the case of Wynberg v. Ontario.

Ontario Ministry of Education. (2002). Transition planning: A resource guide. Retrieved from http://www.edu.gov.on.ca/eng/general/elemsec/speced/transiti/transition.pdf

Ontario Ministry of Education. (2004). The individual education plan (IEP): A resource guide. Retrieved from http://www.edu.gov.on.ca/eng/general/elemsec/speced/guide/resource/iepresguid.pdf Ontario Ministry of Education. (2005a). Education for all: The report of the expert panel on literacy and numeracy instruction for students with special education needs, kindergarten to grade 6. Retrieved from http://www.edu.gov.on.ca/eng/document/reports/speced/panel/speced.pdf

Ontario Ministry of Education. (2005b). Planning entry to school: A resource guide. Retrieved from http://www.edu.gov.on.ca/eng/parents/planningentry.pdf

Ontario Ministry of Education. (2006). Special education transformation: The report of the cochairs with the recommendations of the working table on special education. Retrieved from http://www.edu.gov.on.ca/eng/document/reports/speced/transformation/transformation.pd f

Ontario Ministry of Education. (2007). Policy/program memorandum no. 140. Retrieved from http://www.edu.gov.on.ca/extra/eng/ppm/140.html\#2 
Ontario Ministry of Education. (2009). Equity and inclusive education in Ontario school;

Guidelines for policy development and implementation. Retrieved from

http://www.edu.gov.on.ca/eng/policyfunding/inclusiveguide.pdf

Ontario Ministry of Education. (2011). Results-based plan 2011/12. Retrieved from

http://www.edu.gov.on.ca/eng/about/annualreport

Ortega, F. (2009). The cerebral subject and the challenge of neurodiversity. BioSocieties, 4, 425445.

Owren, T., \& Stenhammer, T. (2013). Neurodiversity: Accepting autistic difference. Learning Disability Practice, 16(4), 32-37.

Parrott, K. A., Schuster, J. W., Collins, B. C., \& Gassaway, L. J. (2000). Simultaneous prompting and instructive feedback when teaching chained tasks. Journal of Behavioral Education, 10, 3-19.

Pettigrew, T. F. (1979). The ultimate attribution error: Extending Allport's cognitive analysis of prejudice. Personality and Social Psychology Bulletin, 5(4), 461-476.

Purdue, K. (2009). Barriers to and facilitators of inclusion for children with disabilities in early childhood education. Contemporary Issues in Early Childhood, 10(2), 133-413.

Ravitch, S., \& Riggan, M. (2012). Reason \& rigor: How conceptual frameworks guide research. Thousand Oaks, CA: Sage Publications Inc.

Roulston, K. (2011). Working through challenges in doing interview research. International Journal of Qualitative Methods, 10(4), 348-366.

Ruijs, N. M., \& Peetsma, T., (2008). Effects of inclusion on students with and without special educational needs reviewed. Educational Research Review, 4, 67-79. 
Schneiter, R., \& Devine, M. A. (2001). Reduction of self-injurious behaviors of an individual with autism: Use of a leisure communication book. Therapeutic Recreation Journal, 35(3), 207-219.

Sirlopu, D., Gonzalez, R., Bohner, G., Siebler, F., Ordonez, G., Millar, A., Torres, D., \& De Tezanos-Pinto, P. (2008). Promoting positive attitudes toward people with Down syndrome: The benefit of school inclusion programs. Journal of Applied Social Psychology, 38, 2710-2736.

Skinner, B. F. (1938). The behavior of organisms: An experimental analysis. New York: Appleton-Century-Crofts.

Skinner, B. F. (1989). The origins of cognitive thought. American Psychologist, 44, 13-18.

Skinner, M. E., \& Hales, M. R. (1992). Classroom teachers' "explanations” of student behavior: One possible barrier to the acceptance and use of applied behavior analysis procedures in the schools. Journal of Educational and Psychological Consultation, 3(3), 219-232.

Smith, T. (2001). Discrete trial training in the treatment of autism. Focus on Autism and Other Developmental Disabilities, 16, 86-92.

Spriggs, A. D., Oast, D. L., \& Ayres, K. A. (2007). Using picture activity schedule books to increase on-schedule and on-task behaviors. Education and Training in Developmental Disabilities, 42, 209-233.

Stahmer, A. C., \& Carter, C. (2005). An empirical examination of toddler development in inclusive childcare. Early Childhood Development and Care, 174(4), 321-333.

Stahmer, A. C., Schreibman, L., \& Cunningham, A. B. (2011). Toward a technology of treatment individualization for young children with autism spectrum disorders. Brain Research, 13, 229-239. 
Steege, M. W., Mace, F. C., Perry, L., \& Longenecker, H. (2007). Applied behavior analysis: Beyond discrete trial teaching. Psychology in the Schools, 44, 91-99.

Sundberg, M. L., \& Partington, J. W. (1998). Teaching language to children with autism or other developmental disabilities. Pleasant Hill, CA: Behavior Analysts, Inc.

Surrey Place Centre. (n.d.) School support program services offered. Retrieved from http://www.surreyplace.on.ca/Clinical-Programs/Autism/SSP/Pages/SSP-Services.aspx

United Nations Educational, Scientific and Cultural Organization. (2005). Guidelines for inclusion: Ensuring access to education for all. Retrieved from http://unesdoc.unesco.org/images/0014/001402/140224e.pdf

Weinkauf, S. M., Zeug, N. M., Anderson, C. T., \& Ala'i-Rosale, S. (2010). Evaluating the effectiveness of a comprehensive staff training package for behavioral interventions for children with autism. Research in Autism Spectrum Disorders, 5, 864-871.

Whatley, A. D., Gast, D. L., \& Hammond, D. L. (2009). Visual activity schedules: Teaching independent transitioning during recreation and leisure. Therapeutic Recreation Journal, $43(2), 27-42$.

Whitaker, P. (2007). Provisions for youngsters with autistic spectrum disorders in mainstream schools: What parents say - and what parents want. British Journal of Special Education, 34(3), 170-178.

World Health Organization. (2002). Towards a common language for functioning, disability and health. Retrieved from http://www.who.int/classifications/icf/training/icfbeginnersguide.pdf

Zachor, D. A., Ben-Itschak, B., Rabinovich, A.-L., \& Lahat, E. (2007). Change in autism core symptoms with intervention. Research on Autism Spectrum Disorders, 1, 304-317. 